\title{
SATISFAÇÃO DOS USUÁRIOS DO RESTAURANTE UNIVERSITÁ- RIO DA UNIVERSIDADE FEDERAL DE SANTA MARIA: UMA ANÁLISE DESCRITIVA
}

\author{
ASATISFACTION OF USERS OF UNIVERSITY RESTAURANT AT THE \\ FEDERALUNIVERSITY OF SANTA MARIA: A DESCRIPTIVE ANALYSIS
}

\author{
Fernando de Jesus Moreira Junior ${ }^{1}$, Caroline Pafiadache ${ }^{2}$, \\ Lais Helen Loose ${ }^{3}$, Rafael Piaia ${ }^{4}$, Vinícius Teodoro Scher ${ }^{5}$, \\ Angelica Peripolli ${ }^{6}$ e Bruna Palm ${ }^{7}$
}

Recebido em: 19/07/2014 Aprovado em: 16/06/2015

\section{RESUMO}

Esta pesquisa tem como objetivo avaliar o nível de satisfação dos usuários do Restaurante Universitário (RU) da Universidade Federal de Santa Maria (UFSM), Rio Grande do Sul, por meio de métodos estatísticos descritivos. Para isso, elaborou-se um questionário com questões sobre perfil e avaliação da satisfação e da importância em relação a 41 itens relacionados ao RU. Participaram da pesquisa 1.855 usuários, incluindo alunos, docentes e técnicos administrativos. Observou-se que a maioria dos usuários é do sexo feminino, está solteira, situa-se na faixa etária de 17 a 30 anos, é aluno sem o benefício socioeconômico, cursa a graduação e almoça em grupo. A maioria dos respondentes frequenta o restaurante entre o meio dia e uma hora da tarde e pelo menos três vezes por semana, sendo o preço atrativo a principal motivação para frequentá-lo. A maioria dos atributos do RU foi avaliada de forma positiva, com destaque para a iluminação interna, o preço cobrado, a localização, a acessibilidade, as formas de pagamento, o atendimento, o tamanho do restaurante, a organização do buffet, o conforto e o layout. Com relação aos itens avaliados insatisfatoriamente, merecem destaque a ventilação, o abrigo contra o sol e a chuva e os aspectos relacionados com a grande quantidade de usuários. Palavras-chave: Pesquisa de satisfação; Pesquisa de mercado; Restaurante Universitário; Análise quantitativa; Métodos descritivos.

\section{ABSTRACT}

This survey aims to assess the level of satisfaction by users of the University Restaurant at the Federal University of Santa Maria $R S$, through descriptive statistical methods. A questionnaire of profiling, assessment of satisfaction and importance in relation to the 41 items related to the University Restaurant was prepared. The research involved 1,855 users, including students, teachers and administrative staff. It was observed the majority are female, singles, situated in the age group 17-30 years, without socioeconomic benefit, who attend undergraduate and lunch in group. The majority of respondents attended the restaurant between midday and one o'clock, and for at least three times a week, where the attractive price is the main motivation to attend it. Most attributes were evaluated positively, particularly for indoor lighting, the price charged, the location, accessibility, forms of payment, the service, the size of the restaurant, the organization of the buffet, comfort and layout. With respect to items poorly evaluated noteworthy ventilation, shelter from the sun and the rain and the items related to the demand of users.

Keywords: Satisfaction survey; Market research; University Restaurant; Quantitative analysis; Descriptive methods.

'Graduado em Estatística e Mestre em Engenharia de Produção pela Universidade Federal do Rio Grande do Sul (UFRGS) e Doutor em Engenharia de Produção pela Universidade Federal de Santa Catarina (UFSC), Brasil. Docente do Departamento de Estatística da Universidade Federal de Santa Maria (UFSM). E-mail: fmjunior777@yahoo.com.br.

${ }^{2}$ Acadêmica do Curso de Estatística da Universidade Federal de Santa Maria (UFSM), Brasil. E-mail: carolpafiadache@yahoo.com.br.

${ }^{3}$ Acadêmica do Curso de Estatística da Universidade Federal de Santa Maria (UFSM), Brasil. E-mail: laisloose@gmail.com.

${ }^{4}$ Acadêmico do Curso de Estatística da Universidade Federal de Santa Maria (UFSM), Brasil. E-mail: rpiaia@gmail.com.

${ }^{5}$ Acadêmico do Curso de Estatística da Universidade Federal de Santa Maria (UFSM), Brasil. E-mail: profvinimat@hotmail.com.

${ }^{6}$ Acadêmica do Curso de Estatística da Universidade Federal de Santa Maria (UFSM), Brasil. E-mail: angelicaperipolli@gmail.com.

${ }^{7}$ Acadêmica do Curso de Estatística da Universidade Federal de Santa Maria (UFSM), Brasil. E-mail: brunagpalm $@$ gmail.com. 


\section{Introdução}

Em um mundo em que as pessoas estão com seu tempo cada vez mais limitado diante das inúmeras responsabilidades adquiridas, o antigo hábito de fazer todas as refeições em casa vem se tornando algo raro. Nesse sentido, Passador et al. (2006) afirmam que a busca pela praticidade aliada à falta de tempo e à distância entre o local de trabalho e a residência fez com que as pessoas mudassem seus hábitos alimentares, de maneira que muitas começaram a realizar as refeições fora de casa.

Dentro desse contexto, estão os estudantes universitários que possuem uma carga horária extensa e que, muitas vezes morando distante da universidade, acabam optando por fazer suas refeições na própria academia. $\mathrm{O}$ mesmo ocorre com professores e servidores públicos que trabalham na Universidade Federal de Santa Maria (UFSM).

Os Restaurantes Universitários (RU's) têm sua importância fundamentada em três aspectos básicos distintos: o prazer proporcionado pela alimentação; a praticidade, que pode ser aliada tanto ao desejo da refeição quanto à necessidade de alimentar-se; e, por último, a saúde, geralmente ligada a uma necessidade específica do comensal de realizar esta refeição (VIDRIK, 2006). Os RU's são muito importantes para a vida acadêmica, principalmente dos alunos de graduação, muitos dos quais não teriam condições financeiras de se alimentar em restaurantes particulares durante todo o período do curso e, assim, não conseguiriam manter seus estudos.

Diante da importância da presença dos RU's no ambiente acadêmico, torna-se necessário avaliar as condições desse serviço, a fim de verificar se as necessidades básicas de uma unidade de alimentação, relacionadas com qualidade nutricional das refeições, higiene, acomodações, ventilação, dentre outros aspectos, estão sendo atendidas. Uma das ferramentas mais utilizadas para levantar essas informações é a Pesquisa de Mercado, a qual pode ser aplicada entre os usuários do restaurante, na forma de pesquisa de opinião.

Diante disso, esta pesquisa pretende realizar um diagnóstico da situação atual do RU da UFSM, identificando quais os aspectos que estão ou não atendendo às necessidades dos usuários. Sabendo da relevância do RU em termos sociais, econômicos e ambientais, o objetivo deste trabalho consiste, assim, em apresentar um diagnóstico sobre o nível de satisfação dos usuários do RU (considerando as três unidades existentes) da UFSM, com base em indicadores de qualidade, elaborados por meio de métodos estatísticos descritivos, a partir de dados levantados através de uma pesquisa realizada com esses usuários. Os resultados desta pesquisa serão encaminhados à direção do RU e poderão gerar subsídios para a formulação de propostas que visam melhorias (mudanças e/ou adaptações) nos critérios avaliados para que o usuário tenha um serviço que atenda às suas necessidades e expectativas.

\section{Referencial teórico}

O surgimento dos Restaurantes Universitários (RU's) ocorreu na década de 50, quando a Universidade do Brasil iniciou a criação do primeiro RU no Rio de Janeiro. A instituição mantinha ainda em outras faculdades e algumas escolas da cidade restaurantes para atendimento de funcionários e alunos (MEC, 1984).

Em 1963, foi inaugurado o primeiro RU da Universidade Federal de Santa Maria (UFSM), no prédio da Rua Marechal Floriano Peixoto, número 1184, no Centro de Santa Maria, Rio Grande do Sul, onde atualmente funcionam alguns cursos do Centro de Ciências Sociais e Humanas (CCSH). Após 12 anos, ocorreu a inauguração do RU - Campus, em 1975, em Camobi. Em 
2010, iniciaram as atividades do RU Refeitório II, servindo apenas almoço, com a finalidade de diminuir as filas e de garantir a todos o mesmo tempo de almoço. Inicialmente, os serviços do RU eram terceirizados e a produção dos alimentos era feita em cada uma de suas sedes. Em fevereiro de 1984 o RU passou a ser administrado pela UFSM, sendo vinculado e coordenado pela Pró-Reitoria de Assuntos Estudantis (PRAE). Utilizando um sistema de compras e administração centralizado, passou a funcionar como Órgão Suplementar Central da UFSM. Em 1997, a produção passou a concentrar-se no RU Campus, e teve início a implantação do sistema de informatização de acesso ao Restaurante (SRU), por meio de carteiras com códigos de barra. Esse sistema, pioneiro no país, passou a ser utilizado por outras instituições de ensino do Brasil. Considerado um dos maiores restaurantes do sul do país, o RU da UFSM vem buscando, a cada dia, o aperfeiçoamento administrativo e a excelência nos serviços prestados, de forma a garantir qualidade e responsabilidade social.

Atualmente, a UFSM possui três RU's (Campus Refeitório I e Refeitório II, que funcionam das $11 \mathrm{~h} 00 \mathrm{~min}$ às 13h30min e RU Centro, que funciona das $11 \mathrm{~h} 00 \mathrm{~min}$ às $13 \mathrm{~h} 15 \mathrm{~min}$ ) que servem, em média, 5.300 refeições diárias oferecidas a alunos, servidores técnico -administrativos e docentes da UFSM. Para alunos carentes, viabiliza, mediante prévia seleção, as três principais refeições diárias - café da manhã, almoço e jantar - com custo subsidiado em $80 \%$, em qualquer uma das sedes (Campus ou Centro). Já os demais alunos devem optar por uma das sedes e entre almoço e jantar, conforme a localização e o turno do seu curso.

Os restaurantes podem ser divididos em duas categorias: comerciais e de coletividade. $\mathrm{O}$ primeiro engloba os estabelecimentos que atendem indivíduos ou grupos, clientela ocasional ou regular, e são abertos a qualquer tipo de público; o segundo atende uma clientela definida, de direito ou de fato, sendo normalmente localizado no seio da mesma, que é o caso dos RU's (GRÁCIA, 2011).

Restaurantes destinados à alimentação coletiva devem oferecer refeições que atendam a critérios nacionais de qualidade nutricional e sanitária, preservando a saúde do consumidor (VICTÓRIA et al., 2003). O serviço de alimentação em um campus é completamente diferente do que ocorre nos outros tipos de restaurantes. Nos restaurantes tradicionais, o objetivo principal é saborear uma boa refeição, de modo que os clientes vão até lá por causa do estabelecimento em si. No entanto, em um campus universitário, os estudantes estão lá por causa das aulas ou de outras atividades acadêmicas, de forma que poucas pessoas vão para o campus apenas para comer (KLASSEN; KUMAR; TRYBUS, 2005).

O RU convive diariamente com o desafio de manter, a baixo custo, um atendimento de qualidade, devendo empenhar-se para prover uma refeição saudável que atenda às necessidades nutricionais dos usuários. Precisa, assim, oferecer um cardápio qualitativa e quantitativamente variado e equilibrado a fim de manter a saúde de sua clientela, sendo imprescindíveis, ainda, qualidades sensoriais e higiênico-sanitárias, bem como um bom atendimento. No caso de um RU, é preciso que atenda os funcionários e os alunos da universidade durante o cumprimento de suas funções na universidade (MAIA, 2008; OLIVEIRA, ALVES, 2008; BRANDRÃO, GIOVANONI, 2011).

Os RU's no contexto das Instituições Públicas de Ensino Superior representam não só a democratização do espaço universitário, mas uma necessidade para o melhor funcionamento dessas Instituições, sendo, inclusive, responsáveis diretos, em algumas delas, pela redução dos índices de evasão escolar. Trabalhos científicos comprovam, 
por exemplo, que a boa alimentação melhora não só o rendimento acadêmico, como também as condições de vida das pessoas (FONAPRACE, 1997).

Esses estabelecimentos devem se preocupar com as características básicas de um restaurante, como higiene, refeições e atendimento, mas também têm de buscar satisfazer o cliente nas suas necessidades diversas, oferecendo, por exemplo, um ambiente agradável, preços acessíveis e informações sobre o cardápio (BISOGNI; JASTRAN; BLAKE, 2011). Para garantir a satisfação dos clientes, os restaurantes requerem uma metodologia adequada para o monitoramento constante da qualidade percebida do serviço oferecido, sendo para isso necessário um conjunto de conhecimentos sobre muitos aspectos (COUTINHO; MOREIRA; SOUZA, 2005).

Os RU's são Unidades de Alimentação e Nutrição (UAN's) que atuam como ferramentas importantes na assistência estudantil, especialmente para os alunos com baixo poder aquisitivo ou que residem a grandes distâncias do ambiente onde estudam (ROHR; MASIERO; KLIEMANN NETO, 2010), ampliando, assim, a oferta de refeições nutricionalmente balanceadas e seguras, a preços baixos. Esses restaurantes, além de propiciarem uma maior facilidade para o desenvolvimento acadêmico dos alunos, são, principalmente, elementos de grande importância social, pois são um local com poder para ampliar as relações sociais ou até mesmo possibilitar um maior contato entre os alunos, em um período fora da sala de aula, além de contribuírem significativamente para diminuir um dos problemas mais constantes nas universidades públicas: o alto índice de evasão.

A satisfação dos clientes, medida por meio da aplicação de uma pesquisa de mercado, é a maneira mais eficiente de avaliar o desempenho de uma organização. Segundo McDaniel e Gates (2005), a pesquisa de marketing é o principal canal para obter informações oportunas para a tomada de decisão, pois permite fornecer aos tomadores de decisões dados sobre o diagnóstico atual e oferecer ideias sobre as mudanças necessárias.

A pesquisa de satisfação proporciona outros benefícios, como percepção mais positiva dos clientes com relação à empresa (neste caso, usuários do RU com relação ao RU); informações atuais e relevantes quanto às necessidades dos clientes; relação de lealdade por parte dos clientes; e confiança devido à aproximação com a empresa (RU). Além disso, a pesquisa de satisfação também tem como objetivos criar padrões mais adequados de atendimento aos clientes, aumentar o índice de retenção dos mesmos, maximizar a sua satisfação e anular o índice de insatisfação (ROSSI; SLONGO, 1998).

A importância da satisfação do cliente é evidente na avaliação de uma empresa e de sua sobrevivência no mercado global. Segundo Milet (1997), recomenda-se perguntar aos clientes o que eles querem, precisam ou esperam e conhecer como os clientes avaliam os produtos ou serviços que lhes são prestados. $\mathrm{O}$ autor ressalta que o sucesso maior é conseguido pelas organizações que se antecipam aos desejos dos clientes, captando as suas necessidades implícitas e superando suas expectativas.

Conforme afirmam Tontini e Sant'ana (2007), a satisfação do cliente está relacionada com o atendimento de suas necessidades implícitas e explícitas, por meio do conjunto de características ou atributos do serviço ou produto. Dessa forma, torna-se importante identificar como o desempenho dos diferentes atributos está relacionado à satisfação dos clientes.

Há vários estudos relacionados à satisfação de usuários de RU's no Brasil. Vidrik (2006), por exemplo, realizou um grupo focal com 18 estudantes a fim de identificar indicadores de qualidade para o RU da Universidade 
do Sagrado Coração (USC) em Bauru, São Paulo. Grácia (2011) estudou a percepção de 289 usuários do RU da Universidade Federal do Paraná (UFPR) quanto à qualidade da carne moída servida. Coutinho, Moreira e Souza (2005) avaliaram a gestão da qualidade dos serviços prestados pelo RU do Campus III da Universidade Federal da Paraíba (UFPB) do ponto de vista de 75 usuários, em que $56 \%$ deles consideram a qualidade dos serviços do RU ruim ou péssimo. Um estudo no RU (RESTAURANTE UNIVERSITÁRIO, 2013a) da Universidade Federal de Santa Catarina (UFSC) elaborou uma pesquisa de opinião com 3.011 usuários do estabelecimento. Outro estudo no RU (RESTAURANTE UNIVERSITÁRIO, 2013b) da Universidade Estadual de Londrina (UEL) realizou uma pesquisa de opinião com 540 usuários, e uma pesquisa no RU (RESTAURANTE UNIVERSITÁRIO, 2014) da Universidade Federal de Uberlândia (UFU) abordou 530 usuários em três campi. Alves e Salcedo (2014) avaliaram o nível de satisfação de 50 usuários do RU da Universidade Federal de Pernambuco (UFPE). Ross, Sartori e Godoy (2009) utilizaram o Modelo de Kano como alternativa para a medição do grau de satisfação de atributos de um RU localizado na região central no estado do Rio Grande do Sul, realizando uma pesquisa com 146 usuários desse ambiente. Cattafesta et al. (2012) estudaram as condições higiênico-sanitárias de um RU e as práticas alimentares de 208 usuários. Medeiros et al. (2013) efetuaram um estudo no RU da Universidade Federal do Rio Grande do Norte (UFRN) com o objetivo de propor melhorias no processo que está diretamente relacionado com os usuários, aplicando o questionário a uma amostra de 73 usuários. Maia (2008) apresenta os resultados de destaque de três pesquisas em que foi avaliado o nível de satisfação dos usuários do RU da Universidade Federal do Ceará (UFC) nos anos de 2003, 2004 e 2005.
Almeida et al. (2008) investigaram a relação entre o cardápio do RU da Universidade Estadual de Campinas (UNICAMP) e o desperdício gerado, em uma amostra de 78 usuários. Hárter et al. (2013) realizaram um estudo de caso sobre a satisfação dos usuários do RU da Universidade Federal de Mato Grosso (UFMT), aplicando um questionário a uma amostra de 100 usuários. Braga, Pereira e Andrade Junior (2015) avaliaram a satisfação dos usuários do RU da Universidade Tecnológica Federal do Paraná (UTFPR) Campus Ponta Grossa, aplicando um questionário a 400 usuários do estabelecimento. Carvalho, Amorim e Tavares (2003) elaboraram um sistema de indicadores de qualidade para o RU da Universidade Federal Fluminense (UFF), com base no grau de satisfação de 71 usuários do RU. Moura et al. (2015) avaliaram a satisfação de 60 alunos usuários do RU da Universidade Federal do Piauí (UFPI) do Campus Ministro Reis Velloso, em Parnaíba. Garcez, Fachin e Andrade Junior (2000) avaliaram o grau de satisfação de 750 usuários do RU da Universidade Federal de Santa Catarina (UFSC). Em uma pesquisa mais recente, Jacob et al. (2006) avaliaram a satisfação dos clientes e o diagnóstico de filas no RU Noturno da UFSC. Gardin e Cruvinel (2014) analisaram a satisfação de 217 usuários do RU do Campus Londrina da Universidade Tecnológica Federal do Paraná (UFTPR). Caixeta e Cunha (1994) fizeram um estudo piloto no RU da Universidade de Brasília (UnB) em dois momentos, o primeiro com 75 usuários, e $\mathrm{o}$ segundo, após implantação de mudanças, com 136 usuários, constatando que houve melhorias com relação a diversos aspectos. Gasparin et al. (2012) estudaram o perfil nutricional e a percepção de conforto de 116 usuários do RU do Campus Medianeira da UTFPR, bem como de 189 clientes de restaurantes de buffet por quilo em seu estudo. Em uma pesquisa realizada por Marques, Pereira e Alves (2010) para identificar os prin- 
cipais fatores relacionados à satisfação quanto à infraestrutura da UFSM, foi verificado que o fator mais importante para os alunos e que apresentou o maior índice de satisfação de toda a análise é o $\mathrm{RU}$, envolvendo a higiene, as refeições e o espaço físico.

Não há, contudo, muitos estudos internacionais relacionados à satisfação de usuários de RU's. Edwards e Meiselman (2005) analisaram a influência de sugestões positivas e negativas sobre a escolha da comida e aceitação de alimentos em um restaurante universitário e verificaram que apenas declarações negativas influenciam a escolha da comida; apesar disso, uma vez que um usuário escolhia um prato, a aceitabilidade desse prato não era afetada. Há alguns estudos sobre estratégias incentivando as pessoas a escolher uma opção saudável em RU's (ALMANZA et al., 1993), em que a divulgação da informação nutricional no ponto de venda resultou em uma maior satisfação dos usuários que passaram a utilizar essa informação na escolha dos alimentos, reduzindo porções de alimentos gordurosos e aumentando o consumo de alimentos mais saudáveis (CRANAGE, CONKLIN, LAMBERT, 2004; FREEDMAN, 2011). As percepções dos usuários em relação às práticas verdes em um restaurante em um campus universitário nos Estados Unidos foi objeto de pesquisa de Di Pietro, Cao e Partlow (2013), que verificaram o interesse dos usuários por restaurantes que se preocupam com a preservação do meio ambiente.Outros estudos (SARAIVA, CID, BAIÃO, 2011; KONG, JAMIL, 2015; NG, 2005) avaliam restaurantes que atendem à comunidade universitária (university food service), mas não se caracterizam como os RU's brasileiros, que atendem a uma grande quantidade de usuários e com preço subsidiado.

\section{Método}

Segundo Gil (2002), uma pesquisa descritiva tem como um dos seus objetivos descrever as características de determinada população ou fenômeno. Richardson (1999) afirma que os estudos de natureza descritiva visam descobrir as características de um fenômeno e podem utilizar como objeto de estudo um indivíduo, um grupo ou uma situação específica. Esse tipo de estudo deve ser realizado quando o pesquisador deseja obter melhor entendimento acerca do comportamento de diversos fatores e elementos que influenciam determinado fenômeno. Malhotra (2001), por sua vez, define a pesquisa descritiva como um tipo de pesquisa conclusiva, que procura explicar a natureza e a especificidade dos fenômenos organizacionais e sociais, permitindo descrever as características de grupos relevantes, estimar a porcentagem de unidades em uma população específica que exibe determinado comportamento, averiguar as percepções de características de produtos, mensurar o grau de associação das variáveis e fazer previsões específicas.

O presente estudo é um survey com propósito descritivo e transversal, que usa de uma amostra não probabilística composta de usuários do Restaurante Universitário (RU) da Universidade Federal de Santa Maria (UFSM), o que inclui estudantes de graduação, mestrado e doutorado, técnicos administrativos e docentes.

A pesquisa foi realizada por meio de um questionário quantitativo baseado nos seguintes autores: Carvalho, Amorim e Tavares (2003), Siebeneichler et al. (2008) e Garcez, Fachin e Andrade Junior (2000). O questionário era autoaplicável e foi enviado de forma eletrônica ao público-alvo, cujos e-mails estavam cadastrados no Sistema de Informações para o Ensino (SIE) da UFSM. O formulário foi elaborado utilizando o aplicativo Google Docs (www. google.com/docs).Segundo McDaniel e 
Gates (2005), os índices de resposta das pesquisas aplicadas por meio da internet variam entre $30 \%$ e $60 \%$. Considerando que o RU (RESTAURANTE UNIVERSITÁRIO, 2012) serve em média 3.650 almoços diários, esperava-se obter uma amostra de, pelo menos, 1.095 usuários. No entanto, a aplicação da pesquisa superou as expectativas, tendo sido respondida por 1.855 usuários.

$\mathrm{O}$ questionário aplicado foi dividido em três partes: a primeira sobre in- formações do perfil do usuário; a segunda sobre o nível de satisfação do usuário em relação a 41 aspectos relacionados aos RU's; e a terceira sobre a importância atribuída pelos usuários a esses 41 aspectos. Este artigo se delimita a analisar de forma descritiva apenas o nível de satisfação dos usuários em relação a esses 41 aspectos. Dessa forma, os usuários avaliaram a sua satisfação em relação aos 41 aspectos utilizando a escala likert apresentada na Tabela 1, a seguir.

Tabela 1 - Escala de satisfação utilizada

\begin{tabular}{c|c|c|c|c}
\hline $\begin{array}{c}\text { Muito } \\
\text { insatisfeito }\end{array}$ & Insatisfeito & $\begin{array}{c}\text { Indiferente } \\
\text { (nem satisfeito } \\
\text { nem insatisfeito) }\end{array}$ & Satisfeito & $\begin{array}{c}\text { Muito } \\
\text { Satisfeito }\end{array}$ \\
\hline 1 & 2 & 3 & 4 & 5 \\
\hline
\end{tabular}

Fonte: Elaborado pelos autores.

Um espaço para críticas, elogios e sugestões foi adicionado ao final da pesquisa. As respostas foram separadas por expressões-chave e, em seguida, foram organizadas em categorias temáticas e apresentadas sob a forma de um resumo, coletando-se a respectiva ideia central considerada mais significativa - os principais resultados foram descritos neste trabalho.

Esta pesquisa também foi divulgada na página oficial da UFSM, em redes sociais e em cartazes fixados em pontos do campus universitário em que havia grande circulação de pessoas. O questionário esteve à disposição para ser respondido pelos frequentadores do RU, sendo estes alunos de graduação e pós-graduação, docentes, servidores e técnicos administrativos que frequentam o RU no horário do almoço, entre os dias 16 de janeiro e primeiro de fevereiro de 2013.

As atividades relativas a esta pesquisa foram desenvolvidas nos laboratórios de Estatística situados no Centro de Ciências Naturais e Exatas (CCNE) da UFSM. Para análise dos dados, foram utilizados os softwares estatísticos Statistica 9.0 e Statistical Package for the Social Science - SPSS 17.0. Os dados omissos, ou seja, as perguntas que não obtiveram resposta, não foram avaliadas; logo, as análises foram baseadas apenas nas respostas válidas.

Esta pesquisa foi aprovada pelo Comitê de Ética em Pesquisa da UFSM, e o projeto foi registrado sob o número 033168.

\section{Apresentação/discussão dos resulta- dos e comparação com outros estudos}

Participaram da pesquisa 1.855 usuários do Restaurante Universitário (RU) da Universidade Federal de Santa Maria (UFSM), sendo esse um número que superou as expectativas da equipe de pesquisa. Desses respondentes, $41,35 \%$ são homens e $58,65 \%$ mulheres. Em relação ao estado civil, a maioria é composta de solteiros $(85,61 \%)$, seguida de casados $(12,61 \%)$, de divorciados $(1,78 \%)$ e de viúvos $(0,27 \%)$.

Quanto ao vínculo com a UFSM, $92,14 \%$ são alunos (dos quais 23,03\% têm benefício socioeconômico), $6,85 \%$ são servidores técnicos administrativos e 1,02\% são docentes. Dentre os alunos, $72,61 \%$ cursam a graduação, $17,41 \%$ a pós-graduação, $1,24 \%$ realiza um curso técnico e $0,86 \%$ está no ensino médio cerca de $8 \%$ não responderam que curso frequentam. 
A maioria dos usuários declarou que almoça em grupo $(76,17 \%)$ e apenas $4,2 \%$ alegaram ser vegetarianos. Outras pesquisas com usuários de RU's apontam diferentes percentuais de vegetarianos. Dentre os usuários do RU da Universidade Federal do Paraná (UFPR), o percentual de vegetarianos é de apenas 2,4\% (GRÁCIA, 2011); nos RU's da Universidade Federal de
Uberlândia (UFU), o percentual é de 8\% (RESTAURANTE UNIVERSITÁRIO, 2014); e no RU da Universidade Federal de Santa Catarina (UFSC), esse percentual sobe para 15\% (RESTAURANTE UNIVERSITÁRIO, 2013a).

Ao analisar a faixa etária dos usuários do RU representada pela Figura 1 , nota-se que $71,86 \%$ são jovens com idade entre 17 e 25.

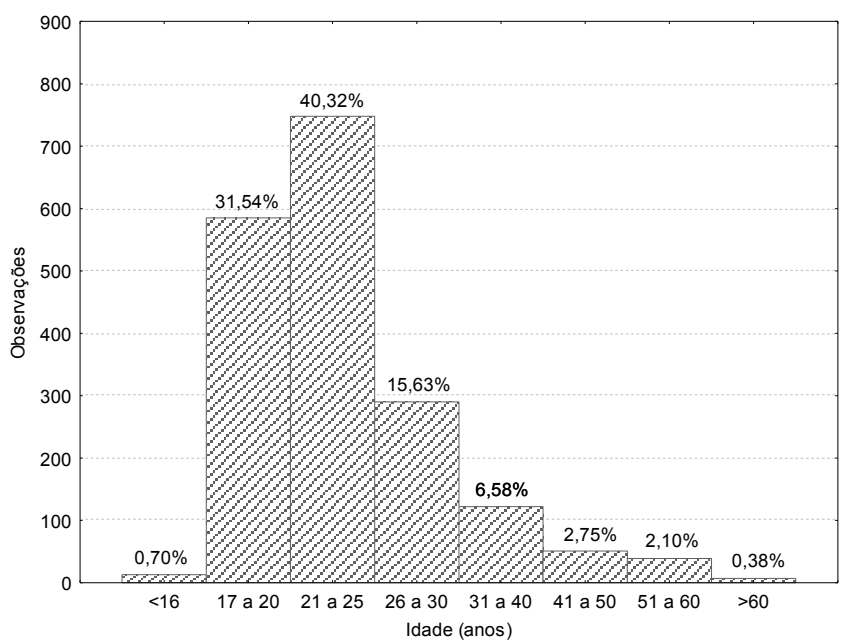

Figura 1 - Histograma da faixa etária dos usuários do RU

Fonte: Elaborado pelos autores.

Dentre os frequentadores do RU, $34,5 \%$ almoçam antes do meio-dia, já $58,44 \%$ preferem fazer esta refeição no intervalo do meio-dia às 13 horas, restando uma pequena parcela de $7,06 \%$ que opta por almoçar após as 13 horas. Com relação à frequência, $44,47 \%$ dos usuários almoçam diariamente no RU, $31,54 \%$ de três a quatro vezes por semana, $10,73 \%$ duas vezes por semana, $1,89 \%$ uma vez por semana e $11,37 \%$ almoçam eventualmente no RU, conforme mostra a Figura 2, a seguir. Esses resultados corroboram o levantamento de Grácia (2011), realizado com usuários do RU da UFPR, em que 68,3\% almoçam entre quatro e cinco dias por semana, $24,0 \%$ entre dois e três dias, $3,5 \%$ um dia e $4,2 \%$ esporadicamente. O levantamento realizado pelo RU (2013a) da UFSC aponta resultados parecidos: $47 \%$ dos usuários almoçam pelo menos cinco dias na semana, $31 \%$ de três a quatro vezes por semana, $11 \%$ duas vezes por semana e $9 \%$ uma vez por semana. No estudo de Cattafesta et al. (2012), 86,1\% dos usuários utilizam o RU pelo menos três vezes por semana. Já no estudo de Maia (2008), $60,4 \%$ dos usuários utilizavam o RU da Universidade Federal do Ceará (UFC) quatro dias na semana em 2003, 44,2\% utilizavam o RU diariamente em $2004 \mathrm{e}$ $46,3 \%$ iam ao restaurante todos os dias em 2005. Já na pesquisa de Medeiros et al. (2013), apenas $27 \%$ dos usuários almoçam diariamente no RU da Universidade Federal do Rio Grande no Norte (UFRN), $19 \%$ de 2 a 4 vezes, $11 \%$ uma vez por semana e $42 \%$ eventualmente. Cerca de $87 \%$ dos usuários do RU da Universidade Federal de Mato Grosso (UFMT) afirmaram frequentar sempre ou frequentemente o RU, enquanto que $13 \%$ frequentam às vezes ou raramente, conforme Hárter et al. (2013). 


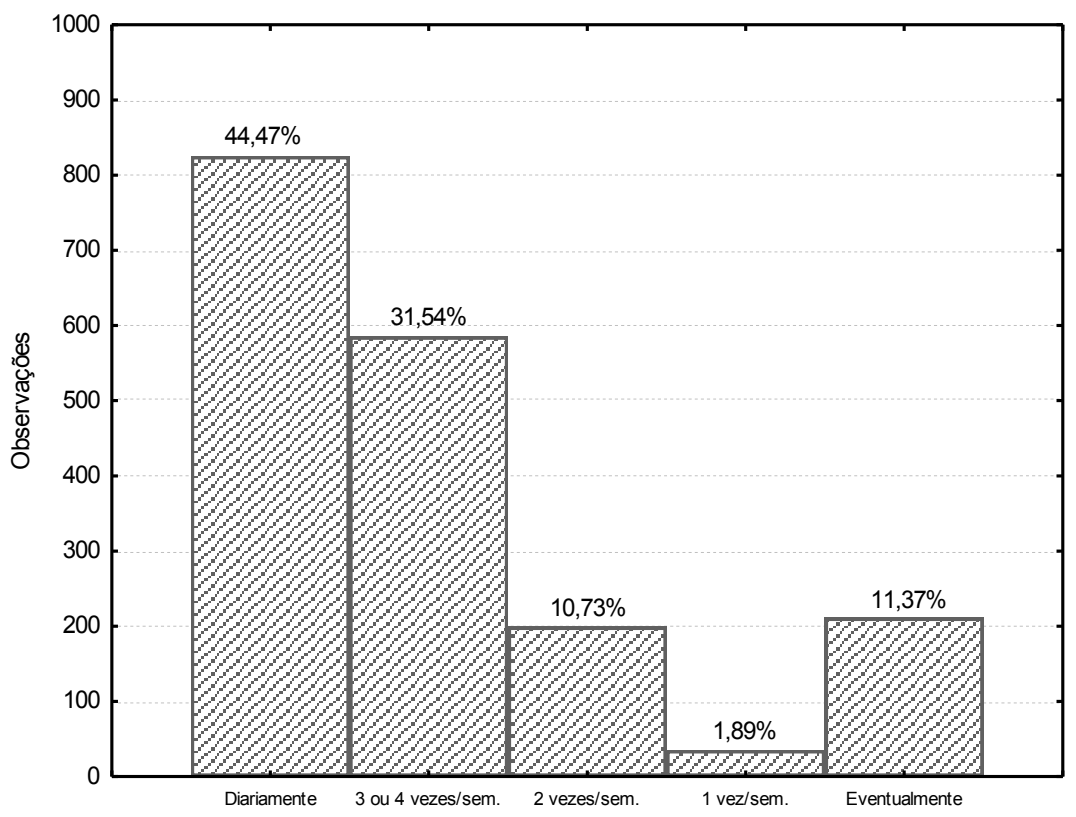

Figura 2 - Frequência com que o usuário almoça no RU Fonte: Elaborado pelos autores.

O restaurante em que o usuário almoça é predefinido pelo curso no qual o mesmo está matriculado, de modo que o usuário não pode escolher o restaurante em que irá almoçar. Dessa forma, a maioria $(89,9 \%)$ almoça no campus localizado no bairro Camobi (50,9\% no Restaurante I e $38,9 \%$ no Restaurante II), enquanto que apenas $10,1 \%$ almoçam no RU localizado no Centro de Santa Maria. A maioria dos usuários opta pelo RU devido ao pelo preço atrativo das refeições $(58,3 \%)$; outros $21,5 \%$ almoçam no estabelecimento por estar localizado próximo do local da aula, da bolsa ou do trabalho; $7,1 \%$ dos usuários escolhem o RU para almoçar devido à qualidade das refeições; $6,6 \%$ devido à alimentação saudável proporcionada; e 6,5\% devido a outros motivos. O preço baixo também é o principal motivo dos usuários fazerem suas refeições em outros RU's do país, como na UFPR (GRÁCIA, 2011), na UFRN (MEDEIROS et al., 2013), na Universidade de Brasília (UNB) (CAIXETA; CUNHA, 1994) e na UFC (MAIA, 2008). A Tabela 2 apresenta a frequência em relação ao principal motivo pelo qual o usuário almoça no RU.

Tabela 2 - Frequência x Motivo principal

\begin{tabular}{cccccc}
\hline $\begin{array}{c}\text { Frequência x } \\
\text { Motivo }\end{array}$ & $\begin{array}{c}\text { Preço } \\
\text { atrati- } \\
\text { vo }\end{array}$ & $\begin{array}{c}\text { Qualidade } \\
\text { das refei- } \\
\text { ções }\end{array}$ & $\begin{array}{c}\text { Localização } \\
\text { (próximo do } \\
\text { local de aula/ } \\
\text { bolsa/ trabalho) }\end{array}$ & $\begin{array}{c}\text { Alimenta- } \\
\text { ção saudá- } \\
\text { vel }\end{array}$ & Outra \\
\hline Diariamente & $60,1 \%$ & $6,4 \%$ & $17,2 \%$ & $9,0 \%$ & $7,3 \%$ \\
3 ou 4x por semana & $62,1 \%$ & $6,2 \%$ & $21,7 \%$ & $3,9 \%$ & $6,2 \%$ \\
2x semana & $50,3 \%$ & $8,0 \%$ & $33,2 \%$ & $3,5 \%$ & $5,0 \%$ \\
1x por semana & $45,7 \%$ & $20,0 \%$ & $28,6 \%$ & $5,7 \%$ & $0,0 \%$ \\
Eventualmente & $50,2 \%$ & $9,5 \%$ & $25,6 \%$ & $8,1 \%$ & $6,6 \%$ \\
TOTAL & $58,3 \%$ & $7,1 \%$ & $21,5 \%$ & $6,6 \%$ & $6,5 \%$ \\
\hline
\end{tabular}

Fonte: Elaborado pelos autores. 

ANGELICA PERIPOLLI E BRUNA PALM

Conforme a Tabela 2, os usuários que frequentam o RU três ou mais vezes por semana são fortemente estimulados pelo preço atrativo. Aqueles que almoçam uma ou duas vezes por semana também são atraídos principalmente pelo preço, mas concedem maior importância com relação à localização do RU. Dos usuários que almoçam uma vez por semana, $20 \%$ o fazem devido à qualidade das refeições. A alimentação saudável é o motivo principal de $9,0 \%$ daqueles que almoçam diariamente e de $8,1 \%$ daqueles que o fazem eventualmente.
As Tabelas 3, 5, 7 e 9 apresentam o percentual do nível de satisfação dos usuários do RU, enquanto que as Tabelas 4, 6, 8 e 10 apresentam a estatística descritiva para cada atributo avaliado no RU. Considerando os 41 itens avaliados, encontrou-se um Alfa de Cronbach igual a 0,93 , o que significa que existe uma forte consistência interna entre esses itens.

A Tabela 3 apresenta a distribuição do nível de satisfação dos dez atributos relacionados com o ambiente interno dos RU's da UFSM. O coeficiente Alfa de Cronbach para esses atributos foi de 0,80 .

Tabela 3 - Análise do ambiente interno do RU

\begin{tabular}{cccccc}
\hline Atributo & $\begin{array}{c}\text { Muito } \\
\text { insatisfeito }\end{array}$ & Insatisfeito & $\begin{array}{c}\text { Indiferente } \\
\text { (nem satisfeito } \\
\text { nem insatisfeito) }\end{array}$ & Satisfeito & $\begin{array}{c}\text { Muito } \\
\text { Satisfeito }\end{array}$ \\
\hline Tamanho/estrutura & $2,43 \%$ & $18,96 \%$ & $15,94 \%$ & $52,46 \%$ & $10,21 \%$ \\
Layout & $3,29 \%$ & $19,30 \%$ & $17,09 \%$ & $50,46 \%$ & $9,87 \%$ \\
Limpeza & $1,84 \%$ & $9,85 \%$ & $13,16 \%$ & $57,61 \%$ & $17,54 \%$ \\
Iluminação & $0,92 \%$ & $2,76 \%$ & $9,15 \%$ & $61,78 \%$ & $25,39 \%$ \\
Odores/cheiros & $10,03 \%$ & $20,43 \%$ & $21,19 \%$ & $37,45 \%$ & $10,89 \%$ \\
Ventilação & $12,30 \%$ & $25,75 \%$ & $11,87 \%$ & $38,59 \%$ & $11,49 \%$ \\
Conforto & $3,31 \%$ & $11,65 \%$ & $19,78 \%$ & $51,33 \%$ & $13,93 \%$ \\
Barulhos & $10,75 \%$ & $28,01 \%$ & $33,93 \%$ & $23,07 \%$ & $4,23 \%$ \\
Decoração & $4,87 \%$ & $11,90 \%$ & $50,11 \%$ & $26,19 \%$ & $6,93 \%$ \\
Banheiro & $13,11 \%$ & $23,29 \%$ & $34,80 \%$ & $24,78 \%$ & $4,02 \%$ \\
\hline
\end{tabular}

Fonte: Elaborado pelos autores.

$\mathrm{O}$ item "tamanho e a estrutura dos restaurantes" obteve $62,67 \%$ de satisfação, percentual maior que no RU (2013b) da Universidade Estadual de Londrina (UEL), onde $50 \%$ consideram a adequação da área física aceitável, boa ou ótima, e maior que no RU da Universidade Federal de Pernambuco (UFPE), onde apenas 30\% consideram satisfatório o arranjo físico, análise que incluiu quantidade de lugares e tamanho, segundo Alves e Salcedo (2014). Já no RU da UFMT, a nota média de satisfação (em uma escala de 0 a 10) para o espaço físico foi de 7,01, conforme Hárter et al. (2013). No RU do Campus Ponta Grossa da Universidade Tecnológica Federal do Paraná (UFTPR), $75,75 \%$ consideram ruim o espaço físico, sendo esse o item com pior nível de satisfação na pesquisa de Braga, Pe- reira e Andrade Junior (2015). No RU da UFSC, esse percentual foi de apenas $2,9 \%$, conforme Garcez, Fachin e Andrade Junior (2000).

$\mathrm{O}$ item layout, relacionado com a distribuição das mesas e das cadeiras, o espaço para circulação e o buffet e com outros aspectos de distribuição física, obteve $60,33 \%$ de satisfação. No RU do Campus Londrina da UTFPR, 43,9\% consideraram bom ou ótimo esse item, conforme Gardin e Cruvinel (2014).

A limpeza do espaço físico interno apresenta um percentual de $75,15 \%$ de satisfação, um percentual muito bom se comparado com outros RU's, como o RU do Campus III da Universidade Federal da Paraíba (UFPB), onde apenas 16\% consideram boa a higiene do ambiente, conforme Coutinho, Moreira e Souza (2005), o RU (2013b) da UEL, onde 
$56 \%$ consideram a higiene do ambiente boa ou ótima, o RU do Campus Ministro Reis Velloso da Universidade Federal do Piauí (UFPI), onde 65,0\% consideram boa ou ótima a higiene do RU, de acordo com Moura et al. (2015), e o RU avaliado por Cattafesta et al. (2012), onde $62,5 \%$ dos usuários atribuíram nota menor que sete(em uma escala entre 0 e 10) às condições higiênico-sanitárias do RU. Já no RU (2014) da UFU, 85\% mostraram-se satisfeitos com a limpeza do refeitório. Segundo Maia (2008), 62,7\% dos usuários sugerem melhoria na limpeza e na manutenção do RU da UFC. No RU do Campus Ponta Grossa da UFTPR, cerca de $27 \%$ não estão satisfeitos com a limpeza, segundo Braga, Pereira e Andrade Junior (2015); já no RU da UFSC, esse percentual foi de apenas $1,5 \%$, conforme Garcez, Fachin e Andrade Junior (2000); no RU noturno da UFSC, foi de apenas $2 \%$, segundo Jacob et al. (2006), e no RU do Campus Londrina da UTFPR, foi de apenas 3,4\%, segundo Gardin e Cruvinel (2014).

A iluminação do ambiente interno possui um percentual de satisfação de $87,17 \%$ dentre os usuários do RU, o que mostra que o local possui boa iluminação interna durante o almoço. Já no RU da Universidade Federal Fluminense (UFF), a iluminação obteve um índice de insatisfação de $52,2 \%$, segundo Carvalho, Amorim e Tavares (2003).

A questão da ventilação apresenta um elevado índice de insatisfação, $38,05 \%$, mesmo com a recente instalação de climatizadores. Isso se justifica pelo fato de que a temperatura dentro dos RU's, durante o verão, passa dos 40 graus Celsius, tornando o almoço uma tarefa árdua. Nesse contexto, merece destaque o RU II, que possui um telhado de zinco que absorve o calor do sol para o ambiente interno. Houve relatos de melhoria na temperatura interna, devido à instalação dos ventiladores, mas alguns usuários disseram que os climatizadores não são suficientes nos dias quentes. Além disso, a instalação dos climatizadores trouxe alguns problemas, como guardanapos e embalagens "voando", aumentando a sujeira no ambiente. No RU da UFMT, a nota média de satisfação (em uma escala de 0 a 10) para a climatização foi de 7,30 , conforme Hárter et al. (2013). No RU do Campus Ponta Grossa da UFTPR, apenas $4 \%$ consideram a ventilação ruim, segundo Braga, Pereira e Andrade Junior (2015), e, no RU do Campus Londrina da UTFPR, esse percentual foi de $21,9 \%$, conforme Gardin e Cruvinel (2014). No RU da UFSC, 32,8\% consideram ruim a ventilação, segundo Garcez, Fachin e Andrade Junior (2000). No RU da UFF, a ventilação obteve um índice de insatisfação de $52,2 \%$, segundo Carvalho, Amorim e Tavares (2003).

O conforto deixa $65,26 \%$ dos usuários satisfeitos, tendo sido sugerida, mesmo assim, a aquisição de algumas mesas mais altas e de cadeiras para melhorar a postura dos usuários altos.Além disso, ressaltou-se a necessidade de aquisição de mesas e cadeiras para pessoas com necessidades especiais. No RU do Campus Ministro Reis Velloso da UFPI, apenas $35,0 \%$ consideram bom ou ótimo o conforto, de acordo com Moura et al. (2015). Já no RU (2013b) da UEL, 49\% estão satisfeitos com o conforto e $60 \%$ com as condições dos mobiliários. No RU do Campus Ponta Grossa da UFTPR, apenas $13,75 \%$ consideram o mobiliário bom ou ótimo, segundo Braga, Pereira e Andrade Junior (2015); já no RU da UFSC, esse percentual foi de apenas $50,8 \%$, conforme Garcez, Fachin e Andrade Junior (2000). No RU do Campus Medianeira da UTFPR, menos de $20 \%$ consideraram as cadeiras confortáveis e cerca de $30 \%$ consideraram a sala de refeições confortável, segundo Gasparin et al. (2012).

Os barulhos apresentam um índice de insatisfação considerável: $38,76 \%$. No RU do Campus Ponta Grossa da UFTPR, apenas 5\% consideram o barulho ruim, segundo Braga, Pereira e Andrade Junior (2015); porém, no RU da UFSC, esse percentual foi de 
$37,8 \%$, sendo esse o item com o pior nível de satisfação na pesquisa de Garcez, Fachin e Andrade Junior (2000).

Cerca de $36 \%$ dos usuários encontram-se insatisfeitos com os banheiros, havendo queixas quanto à falta de materiais (papel higiênico e sabonete), à presença de umidade, à falta de higiene e à falta de adaptação para deficientes físicos. A higiene dos banheiros foi um fator considerado inaceitável ou insatisfatório por $26 \%$ dos usuários do RU (2013b) da

UEL. Cerca de $30 \%$ incomodam-se com os cheiros e odores, fator que pode estar relacionado com a ventilação.

Chama a atenção o alto índice de usuários $(50,11 \%)$ que se mostram indiferentes com relação à decoração interna, indicando que esse item não interfere em seu almoço. Na Tabela 4, consta uma análise descritiva dos dados obtidos sobre o ambiente interno do RU da UFSM.

Tabela 4 - Análise descritiva dos atributos relacionados ao ambiente interno do RU

\begin{tabular}{cccccc}
\hline Atributos & $\begin{array}{c}\text { Respostas } \\
\text { válidas }\end{array}$ & Média & Mediana & Desvio-padrão & Variância \\
\hline Tamanho/estrutura & 1851 & 3,49 & 4 & 0,990 & 0,980 \\
Layout & 1855 & 3,44 & 4 & 1,014 & 1,028 \\
Limpeza & 1847 & 3,79 & 4 & 0,908 & 0,824 \\
Iluminação & 1847 & 4,08 & 4 & 0,730 & 0,533 \\
Odores/cheiros & 1845 & 3,19 & 3 & 1,175 & 1,381 \\
Ventilação & 1845 & 3,11 & 4 & 1,258 & 1,583 \\
Conforto & 1845 & 3,61 & 4 & 0,974 & 0,949 \\
Barulhos & 1842 & 2,82 & 3 & 1,039 & 1,079 \\
Decoração & 1848 & 3,18 & 3 & 0,905 & 0,819 \\
Banheiro & 1816 & 2,83 & 3 & 1,067 & 1,139 \\
\hline
\end{tabular}

Fonte: Elaborado pelos autores.

Os resultados da Tabela 4 corroboram os resultados da Tabela 3. Nota-se que os barulhos e os banheiros apresentam médias abaixo da categoria indiferente, o que mostra a insatisfação dos usuários com relação a esses itens.

A avaliação dos cinco atributos relacionados ao ambiente externo do RU é representada na Tabela 5. O coeficiente Alfa de Cronbach para esses atributos foi de 0,72 .

Tabela 5 - Análise do ambiente externo do RU

\begin{tabular}{cccccc}
\hline Atributo & $\begin{array}{c}\text { Muito } \\
\text { insatis- } \\
\text { feito }\end{array}$ & $\begin{array}{c}\text { Insatis- } \\
\text { feito }\end{array}$ & $\begin{array}{c}\text { Indiferente } \\
\text { (nem satisfeito nem } \\
\text { insatisfeito) }\end{array}$ & Satisfeito & $\begin{array}{c}\text { Muito } \\
\text { Satisfeito }\end{array}$ \\
\hline Fachada/aparência & $3,86 \%$ & $14,30 \%$ & $38,99 \%$ & $36,16 \%$ & $6,69 \%$ \\
Localização & $2,50 \%$ & $5,92 \%$ & $10,53 \%$ & $54,51 \%$ & $26,55 \%$ \\
Acessibilidade & $4,06 \%$ & $10,64 \%$ & $15,30 \%$ & $54,03 \%$ & $15,96 \%$ \\
Abrigo do sol e chuva & $12,66 \%$ & $30,09 \%$ & $14,94 \%$ & $33,46 \%$ & $8,85 \%$ \\
Sinalização & $5,77 \%$ & $16,69 \%$ & $32,56 \%$ & $38,22 \%$ & $6,75 \%$ \\
\hline
\end{tabular}

Fonte: Elaborado pelos autores.

A Tabela 5 faz uma avaliação dos itens do ambiente externo do RU, onde a presença de um abrigo contra o sol e a chuva é o item com maior índice de insatisfação $(42,75 \%)$. Isso mostra que há uma deficiência na área externa dos RU's para os usuários que ficam na fila do lado de fora do restaurante. No entan- to, esse é um problema encontrado também em outros RU's do país, conforme Coutinho, Moreira e Souza (2005).

Por outro lado, a localização e a acessibilidade possuem altos índices de satisfação: $81,06 \%$ e $69,99 \%$, respectivamente. No Campus Londrina da UTFPR, $43,9 \%$ consideraram bom ou ótimo o 
acesso ao RU, conforme Gardin e Cruvinel (2014). No estudo de Cattafesta et al. (2012), 57,7\% dos usuários avaliaram de 0 a 6 (em uma escala de 0 a 10) a localização do RU. A fachada e a sinalização desta- cam-se pelo elevado índice de indiferença: $38,99 \%$ e $32,56 \%$, respectivamente.

Uma análise descritiva dos dados obtidos sobre o ambiente externo do RU é apresentada na Tabela 6, a seguir.

Tabela 6 - Análise descritiva dos atributos relacionados ao ambiente externo do RU

\begin{tabular}{cccccc}
\hline Atributos & $\begin{array}{c}\text { Respostas } \\
\text { válidas }\end{array}$ & Média & Mediana & Desvio-padrão & Variância \\
\hline Fachada/aparência & 1839 & 3,28 & 3 & 0,923 & 0,851 \\
Localização & 1842 & 3,97 & 4 & 0,912 & 0,832 \\
Acessibilidade & 1823 & 3,67 & 4 & 0,998 & 0,997 \\
Abrigo do sol e chuva & 1841 & 2,96 & 3 & 1,223 & 1,495 \\
Sinalização & 1821 & 3,24 & 3 & 0,998 & 0,995 \\
\hline
\end{tabular}

Fonte: Elaborado pelos autores.

Os resultados da análise descritiva corroboram os resultados das frequências observadas. Quanto à acessibilidade, os usuários sugeriram um melhor acesso ao buffet pelos cadeirantes, pelos portadores de deficiência física e pelas gestantes, assim como a possibilidade de atendimento prioritário para esses grupos. Quanto à sinalização, houve duas sugestões: colocação de placas bilíngues para melhor aces- so de usuários estrangeiros e demarcações nas filas de acesso ao RU, assim como nas filas para se servir e para a devolução dos utensílios, a fim de organizar e melhorar o fluxo de pessoas.

A Tabela 7 apresenta a avaliação do nível de satisfação dos 16 atributos relacionados com a alimentação oferecida pelo RU. O coeficiente Alfa de Cronbach para esses atributos foi de 0,91 .

Tabela 7 - Análise da alimentação do RU

\begin{tabular}{|c|c|c|c|c|c|}
\hline Atributo & $\begin{array}{c}\text { Muito } \\
\text { insatisfeito }\end{array}$ & Insatisfeito & $\begin{array}{l}\text { Indiferente (nem satis- } \\
\text { feito nem insatisfeito) }\end{array}$ & Satisfeito & $\begin{array}{c}\text { Muito } \\
\text { satisfeito } \\
\end{array}$ \\
\hline Organização do buffet & $1,84 \%$ & $8,65 \%$ & $12,71 \%$ & $62,52 \%$ & $14,28 \%$ \\
\hline $\begin{array}{l}\text { Qualidade dos } \\
\text { alimentos }\end{array}$ & $3,80 \%$ & $14,86 \%$ & $13,56 \%$ & $53,20 \%$ & $14,59 \%$ \\
\hline $\begin{array}{l}\text { Temperatura } \\
\text { dos alimentos }\end{array}$ & $2,82 \%$ & $10,57 \%$ & $10,95 \%$ & $59,40 \%$ & $16,26 \%$ \\
\hline $\begin{array}{c}\text { Alimentação equilibrada e } \\
\text { saudável }\end{array}$ & $2,57 \%$ & $7,81 \%$ & $14,15 \%$ & $56,67 \%$ & $18,80 \%$ \\
\hline Sabor e temperos & $14,76 \%$ & $30,05 \%$ & $16,70 \%$ & $30,92 \%$ & $7,57 \%$ \\
\hline Higiene dos alimentos & $2,33 \%$ & $11,29 \%$ & $17,32 \%$ & $55,65 \%$ & $13,41 \%$ \\
\hline Variedade diária & $7,26 \%$ & $22,21 \%$ & $18,31 \%$ & $42,69 \%$ & $9,53 \%$ \\
\hline $\begin{array}{c}\text { Variedade do cardápio } \\
\text { semanal }\end{array}$ & $8,58 \%$ & $23,51 \%$ & $17,75 \%$ & $40,99 \%$ & $9,17 \%$ \\
\hline $\begin{array}{l}\text { Quantidade da porção } \\
\text { da carne }\end{array}$ & $10,72 \%$ & $17,90 \%$ & $15,02 \%$ & $44,72 \%$ & $11,64 \%$ \\
\hline $\begin{array}{c}\text { Quantidade da porção } \\
\text { sobremesa }\end{array}$ & $6,57 \%$ & $13,41 \%$ & $19,11 \%$ & $50,60 \%$ & $10,31 \%$ \\
\hline Salada $(V$ e Q)* & $8,18 \%$ & $23,28 \%$ & $17,28 \%$ & $39,64 \%$ & $11,61 \%$ \\
\hline Arroz $(\mathrm{V}, \mathrm{S}, \mathrm{Q}) *$ & $4,35 \%$ & $10,00 \%$ & $13,15 \%$ & $56,79 \%$ & $15,71 \%$ \\
\hline $\begin{array}{l}\text { Complemento } \\
(\mathrm{V}, \mathrm{S}, \mathrm{Q})^{*}\end{array}$ & $7,14 \%$ & $21,25 \%$ & $18,58 \%$ & $43,65 \%$ & $9,37 \%$ \\
\hline $\begin{array}{l}\text { Feijão/lentilha } \\
(\mathrm{V}, \mathrm{S}, \mathrm{Q})^{*}\end{array}$ & $6,81 \%$ & $16,72 \%$ & $13,67 \%$ & $48,91 \%$ & $13,89 \%$ \\
\hline Carne (V, S, Q)* & $10,06 \%$ & $25,15 \%$ & $17,77 \%$ & $38,87 \%$ & $8,15 \%$ \\
\hline Guisado de soja $(\mathrm{S}, \mathrm{Q})^{*}$ & $12,23 \%$ & $12,06 \%$ & $51,03 \%$ & $18,46 \%$ & $6,23 \%$ \\
\hline
\end{tabular}

(*) Abreviações: $\mathrm{Q}=$ qualidade, $\mathrm{S}=$ sabor, $\mathrm{V}=$ variedade

Fonte: Elaborado pelos autores. 
Observando-se a Tabela 7, verifica-se que há um elevado índice de insatisfação com relação ao sabor e ao tempero $(44,81 \%)$. De fato, muitos usuários reclamaram da falta de tempero e da ausência de um saleiro. No RU da UFPE, segundo Alves e Salcedo (2014), esse índice foi de $48 \%$ e, no RU do Campus Londrina da UTFPR, foi de apenas $12,2 \%$, conforme Gardin e Cruvinel (2014). No RU da UFC, conforme Maia (2008), a média de satisfação desse quesito foi 5,8, em uma escala de 0 a 10 .

Quanto à organização do buffet, $76,80 \%$ mostraram-se satisfeitos, percentual superior ao do RU noturno da UFSC, que foi de 59\%, segundo Jacob et al. (2006).

Cerca de 35\% mostraram-se insatisfeitos com relação à carne servida, $32,09 \%$ com a variedade semanal do cardápio, 29,47\% coma variedade diária, $28,62 \%$ com a quantidade da porção de carne e $28,39 \%$ com o complemento. No RU da Universidade Estadual de Campinas (UNICAMP), 73\% dos usuários consideram que a carne tem um sabor desagradável, sendo a principal responsável pelo desperdício, segundo Almeida et al. (2008). No RU do Campus Londrina da UTFPR, 27,9\% não estão satisfeitos com o tamanho da porção dos alimentos e $22,0 \%$ não se agradam com a variedade, conforme Gardin e Cruvinel (2014). No RU (2013b) da UEL, 12\% dos usuários estão insatisfeitos com a variação do cardápio; já no RU (2014) da UFU, esse percentual é de $15 \%$. No RU da UFC, a média de satisfação desse quesito foi 5,9, em uma escala de 0 a 10, conforme Maia (2008). No RU do Campus Ponta Grossa da UFTPR, 22,5\% consideram ruim a variedade, segundo Braga, Pereira e Andrade Junior (2015). No RU da UFSC, $19,7 \%$ consideram ruim a variedade, segundo Garcez, Fachin e Andrade Junior (2000), ao passo que no RU noturno da UFSC, $16 \%$ consideram ruim a variedade, segundo Jacob et al. (2006). No RU da UFF, a variedade do cardápio obteve um índice de insatisfação de $80,3 \%$, segundo
Carvalho, Amorim e Tavares (2003).

Por outro lado, há elevados índices de satisfação com relação à organização do buffet $(76,8 \%)$, à temperatura dos alimentos $(75,66 \%)$, à presença de alimentos equilibrados e saudáveis $(75,47 \%)$, ao arroz $(72,5 \%)$, à higiene dos alimentos $(69,06 \%)$ e à qualidade dos alimentos $(67,79 \%)$. O bom indicador da higiene dos alimentos contrasta com o RU do Campus III da UFPB, onde apenas 19\% avaliaram esse quesito positivamente, assim como a qualidade das refeições, que obteve $42 \%$ de insatisfação na UFPB, segundo Coutinho, Moreira e Souza (2005). Já no RU (2013b) da UEL, 44\% estão satisfeitos com a qualidade das refeições e $47 \%$ com a conservação dos alimentos. No RU (2014) da UFU, 71\% estão satisfeitos com a qualidade das refeições. No RU da UFC, 67,8\% dos usuários apontam que a melhoria da qualidade das refeições deve ser prioridade nas ações de melhoria do RU, segundo Maia (2008). No RU do Campus Ponta Grossa da UFTPR, apenas 7,5\% dos usuários consideram a higiene dos alimentos boa ou ótima, mas $92,75 \%$ consideram boa ou ótima a qualidade dos alimentos, segundo Braga, Pereira e Andrade Junior (2015). No RU do Campus Ministro Reis Velloso da UFPI, apenas 53,3\% consideram boa ou ótima a qualidade dos alimentos e $31,7 \%$ têm a mesma avaliação quanto à variedade dos pratos, sendo essa a maior deficiência do RU, apontada por $60 \%$ dos entrevistados, de acordo com Moura et al. (2015). No RU da UFSC, 80,3\% dos usuários consideram a higiene dos alimentos boa ou ótima e $85,0 \%$ consideram boa ou ótima a qualidade dos alimentos, conforme Garcez, Fachin e Andrade Junior (2000). Já no RU noturno da UFSC, $68 \%$ consideram boa ou ótima a qualidade dos alimentos, segundo Jacob et al. (2006). No RU do Campus Londrina da UTFPR, a apresentação visual dos alimentos agrada 53,2\% dos usuários, conforme Gardin e Cruvinel (2014). 
A maioria dos usuários se mostrou indiferente com relação ao guisado de soja, opção alternativa aos vegetarianos. Na Tabela 8, consta uma análise descritiva dos dados obtidos sobre os itens relacionados à alimentação oferecida aos usuários do RU.

Tabela 8 - Análise descritiva dos atributos relacionados à alimentação do RU

\begin{tabular}{cccccc}
\hline Atributos & $\begin{array}{c}\text { Respostas } \\
\text { válidas }\end{array}$ & Média & Mediana & Desvio-padrão & Variância \\
\hline Organização do buffet & 1849 & 3,79 & 4 & 0,858 & 0,737 \\
Qualidade dos alimentos & 1844 & 3,60 & 4 & 1,028 & 1,057 \\
Temperatura & 1845 & 3,76 & 4 & 0,943 & 0,890 \\
Alimentação equilibrada e & 1830 & 3,81 & 4 & 0,916 & 0,839 \\
saudável & 1850 & 2,86 & 3 & 1,219 & 1,485 \\
Sabor e temperos & 1842 & 3,67 & 4 & 0,926 & 0,857 \\
Higiene dos alimentos & 1846 & 3,25 & 4 & 1,122 & 1,259 \\
Variedade diária & 1842 & 3,19 & 4 & 1,149 & 1,321 \\
Variedade cardápio & 1838 & 3,29 & 4 & 1,200 & 1,439 \\
Quantidade de carne & 1842 & 3,45 & 4 & 1,057 & 1,116 \\
Quantidade de sobremesa & 1834 & 3,23 & 4 & 1,169 & 1,368 \\
Salada & 1840 & 3,70 & 4 & 0,994 & 0,987 \\
Arroz & 1835 & 3,27 & 4 & 1,113 & 1,238 \\
Complemento & 1836 & 3,46 & 4 & 1,127 & 1,270 \\
Feijão/lentilha & 1829 & 3,10 & 3 & 1,166 & 1,359 \\
Carne & 1750 & 2,94 & 3 & 1,020 & 1,041 \\
Guisado de soja & & & & & \\
\hline
\end{tabular}

Fonte: Elaborado pelos autores.

Avaliando a Tabela 8, constatase que a maioria dos itens foi avaliada como satisfatória e indiferente, com exceção do sabor e tempero e do guisado de soja, que foram avaliados negativamente pela maioria dos usuários. No RU da UFSM, as quantidades de carne e de sobremesa não são definidas pelo usuário, mas sim pelo funcionário do RU que serve essas porções, sendo, geralmente, uma porção (ou um pedaço) de carne e um pote (ou um pacote) de doce ou uma unidade de fruta. Houve algumas reclamações, principalmente em relação à porção da carne, uma vez que alguns gostariam de receber um pedaço maior e outros um pedaço menor, sendo ressaltada a variabilidade do tamanho do pedaço de carne. Também houve algumas críticas principalmente em relação ao peixe e à carne de porco. Outros usuários sugeriram maior varia- ção nas saladas e na carne. Foi sugerido também um vidro no buffet a fim de proteger melhor os alimentos contra impurezas que possam cair sobre eles.

Os valores informados na Tabela 9 representam a avaliação da satisfação dos dez itens relacionados ao atendimento no RU. O coeficiente Alfa de Cronbach para esses atributos foi de 0,79 .

O preço cobrado foi o critério considerado mais satisfatório entre os usuários, com um índice de $85,6 \%$ de satisfação, o que reforça ser esse o principal incentivo para almoçar no RU $(58,27 \%)$, como já mencionado. No RU da UFPE, esse percentual cai para $60 \%$, segundo a pesquisa de Alves e Salcedo (2014). Já no RU da UFMT, a nota média de satisfação (em uma escala de 0 a 10 ) foi de 9,39, sendo o item melhor avaliado na pesquisa de Hárter et al. (2013). Porém, no RU do Campus Ponta Grossa da UF- 
TPR, apenas $40,25 \%$ consideram o preço bom ou ótimo, segundo Braga, Pereira e Andrade Junior (2015), indicador parecido com o do RU da UFSC, que obteve apenas $40,4 \%$ de satisfação, conforme Garcez, Fachin e Andrade Junior (2000). Porém, no RU do Campus Londrina da UTFPR, 76,1\% dos usuários estão satisfeitos com o preço cobrado, conforme Gardin e Cruvinel (2014).

$\mathrm{O}$ atendimento, a postura e a higiene dos funcionários (apresentação dos funcionários) também foram avaliados positivamente pela maioria dos usuários $(70,17 \%)$. Quanto aos usuários do RU (2013b) da UEL, 89\% aprovam o atendimento dos funcionários $\mathrm{e}$, no RU (2014) da UFU, 80\% aprovam. No RU avaliado por Cattafesta et al. (2012), $42,3 \%$ dos usuários avaliaram com nota entre 7 e 10 (em uma escala de 0 a 10) a higiene dos funcionários. Entretanto, na UFPB, apenas $31,5 \%$ dos usuários do RU do Campus III consideraram satisfatória a higiene dos funcionários, segundo Coutinho, Moreira e Souza (2005), assim como no RU da UFPE, onde $46 \%$ consideraram satisfatória a higiene dos funcionários, conforme Alves e Salcedo (2014). No RU da UFC, $62,5 \%$ consideram razoável o atendimento dos funcionários, porém $66,3 \%$ consideram inadequada a higiene dos funcionários, segundo Maia (2008). No RU do Campus Ministro Reis Velloso da UFPI, 56,7\% consideram bom ou ótimo o atendimento dos funcionários, de acordo com Moura et al. (2015). No RU do Campus Londrina da UTFPR, $43,0 \%$ consideraram boa ou ótima a cordialidade dos funcionários e $59 \%$ a pontualidade no atendimento, conforme Gardin e Cruvinel (2014). No RU noturno da UFSC, $80 \%$ estão satisfeitos coma higiene dos funcionários e $72 \%$ com o atendimento, segundo Jacob et al. (2006). Já no RU da UFMT, a nota média de satisfação (em uma escala de 0 a 10) para o atendimento dos funcionários foi de 6,25, conforme Hárter et al. (2013).
As opções de pagamento $(65,41 \%)$, a agilidade na reposição dos alimentos $(64,46 \%)$ e o horário para a compra de créditos $(63,21 \%)$ também foram avaliados positivamente pela maioria. Conforme Alves e Salcedo (2014), a satisfação com as opções de pagamentos cai para $42 \%$ no RU da UFPE. No RU do Campus Londrina da UTFPR, 46,8\% dos usuários consideraram boa ou ótima a rapidez no atendimento, $67,3 \%$ aprovam as opções de pagamento e $79,0 \%$ estão satisfeitos com a organização do caixa, conforme Gardin e Cruvinel (2014).

Por outro lado, há elevados índices de insatisfação com relação ao tamanho da fila para entrar no RU $(49,02 \%)$, ao tamanho da fila para a compra de créditos $(47,29 \%)$ e à disponibilidade de lugar para sentar e almoçar $(46,56 \%)$. Esses itens mostram que os RU's estão com certa deficiência para atender a demanda de usuários. No RU do Campus Londrina da UTFPR, $73,1 \%$ consideraram péssimo, ruim ou regular o tempo de espera na fila do RU, conforme Gardin e Cruvinel (2014).No RU (2013b)da UEL, 84\% dos usuários consideram insatisfatório ou inaceitável o tempo de espera na fila, enquanto que, no RU da UFMT, a nota de satisfação média (em uma escala de 0 a 10) foi de 4,57 para esse quesito, conforme Hárter et al. (2013). O tempo de espera foi o fator mais insatisfatório $(87,2 \%)$ levantado na pesquisa de Carvalho, Amorim e Tavares (2003) quanto ao RU da UFF.

A presente pesquisa também apontou $30,74 \%$ de insatisfeitos com a limpeza dos utensílios e $40,45 \%$ de insatisfeitos com a falta de manutenção do cardápio previsto. No RU do Campus III da UFPB, $43 \%$ dos usuários consideraram essa higiene ruim ou péssima, de acordo com Coutinho, Moreira e Souza (2005); porém, no RU do Campus Londrina da UTFPR, 27,3\% consideraram boa ou ótima essa higiene ruim ou péssima e apenas $15,9 \%$ estão insatisfeitos com a falta de manutenção do cardápio, 
conforme Gardin e Cruvinel (2014). No RU (2014) da UFU, apenas 4\% desaprovam a limpeza dos utensílios; já no
RU noturno da UFSC, esse percentual é de apenas 3\%, segundo Jacob et al. (2006).

Tabela 9 - Análise do atendimento no RU

\begin{tabular}{|c|c|c|c|c|c|}
\hline Atributo & $\begin{array}{c}\text { Muito } \\
\text { insatisfeito }\end{array}$ & $\begin{array}{l}\text { Insatis- } \\
\text { feito }\end{array}$ & $\begin{array}{l}\text { Indiferente (nem } \\
\text { satisfeito nem } \\
\text { insatisfeito) }\end{array}$ & Satisfeito & $\begin{array}{c}\text { Muito } \\
\text { Satisfeito }\end{array}$ \\
\hline $\begin{array}{l}\text { Apresentação dos fun- } \\
\text { cionários }\end{array}$ & $1,89 \%$ & $8,83 \%$ & $19,11 \%$ & $55,28 \%$ & $14,89 \%$ \\
\hline $\begin{array}{l}\text { Agilidade em repor os } \\
\text { alimentos }\end{array}$ & $3,30 \%$ & $16,69 \%$ & $15,56 \%$ & $52,84 \%$ & $11,62 \%$ \\
\hline $\begin{array}{l}\text { Manutenção do cardá- } \\
\text { pio }\end{array}$ & $7,52 \%$ & $22,93 \%$ & $23,26 \%$ & $39,16 \%$ & $7,14 \%$ \\
\hline Preço cobrado & $2,27 \%$ & $4,87 \%$ & $7,25 \%$ & $41,23 \%$ & $44,37 \%$ \\
\hline Opções de pagamento & $5,11 \%$ & $13,65 \%$ & $15,82 \%$ & $42,14 \%$ & $23,27 \%$ \\
\hline $\begin{array}{l}\text { Horário para a compra } \\
\text { de créditos }\end{array}$ & $7,00 \%$ & $16,77 \%$ & $13,02 \%$ & $46,01 \%$ & $17,20 \%$ \\
\hline $\begin{array}{l}\text { Tamanho da fila para a } \\
\text { compra de créditos }\end{array}$ & $17,01 \%$ & $30,28 \%$ & $22,86 \%$ & $24,86 \%$ & $4,98 \%$ \\
\hline $\begin{array}{l}\text { Tamanho da fila para } \\
\text { entrar no RU }\end{array}$ & $18,61 \%$ & $30,41 \%$ & $22,73 \%$ & $24,30 \%$ & $3,95 \%$ \\
\hline $\begin{array}{l}\text { Disponibilidade de lu- } \\
\text { gar para almoçar }\end{array}$ & $13,86 \%$ & $32,70 \%$ & $20,63 \%$ & $29,29 \%$ & $3,52 \%$ \\
\hline Limpeza dos utensílios & $9,31 \%$ & $21,43 \%$ & $17,75 \%$ & $42,15 \%$ & $9,36 \%$ \\
\hline
\end{tabular}

Fonte: Elaborado pelos autores.

Na Tabela 10, consta uma análise descritiva dos dados sobre o atendimento prestado no RU. Os resultados corroboram as conclusões obtidas da Tabela 9.

Tabela 10 - Análise descritiva dos atributos relacionados ao atendimento no RU

\begin{tabular}{|c|c|c|c|c|c|}
\hline Atributos & $\begin{array}{c}\text { Respostas } \\
\text { Válidas }\end{array}$ & Média & Mediana & $\begin{array}{c}\text { Des- } \\
\text { vio-pa- } \\
\text { drão }\end{array}$ & Variância \\
\hline Apresentação pessoal dos funcionários & 1847 & 3,72 & 4 & 0,888 & 0,788 \\
\hline Agilidade na reposição dos alimentos & 1851 & 3,53 & 4 & 1,007 & 1,014 \\
\hline Manutenção do cardápio & 1836 & 3,15 & 3 & 1,088 & 1,184 \\
\hline Preço cobrado & 1848 & 4,21 & 4 & 0,935 & 0,874 \\
\hline Opções de pagamento & 1839 & 3,65 & 4 & 1,129 & 1,274 \\
\hline Horário para a compra de créditos & 1843 & 3,50 & 4 & 1,162 & 1,350 \\
\hline Tamanho da fila para comprar créditos & 1846 & 2,71 & 3 & 1,160 & 1,345 \\
\hline Tamanho da fila para entrar no RU & 1848 & 2,65 & 3 & 1,151 & 1,325 \\
\hline Disponibilidade de lugar para almoçar & 1847 & 2,76 & 3 & 1,121 & 1,258 \\
\hline Limpeza dos utensílios & 1848 & 3,21 & 4 & 1,158 & 1,340 \\
\hline
\end{tabular}

Fonte: Elaborado pelos autores. 
Para resumir os resultados encontrados, foram elaboradas a Figura 3 , que apresenta o percentual de insatisfação total, isto é, a soma das categorias "insatisfeito" e "muito insatisfeito", representado o nível baixo de satisfação; e a Figura 4, que apresenta o percentual de satisfação total, isto é, a soma das categorias "satisfeito" e "muito satisfeito",representado o nível alto de satisfação. Essas figuras oferecem uma visão geral dos resultados encontrados neste trabalho e permitem, além disso, observar o contraste entre a avaliação dos itens, em que, em geral, os itens com maior percentual de satisfação (Figura 4) aparecem com os menores percentuais de insatisfação (Figura 3) e vice-versa. Observa-se que os três maiores percentuais de insatisfação estão relacionados com o elevado número de usuários que frequentam o RU. Por outro lado, os maiores percentuais de satisfação estão relacionados com a iluminação interna, o preço cobrado e a localização dos RU's. 


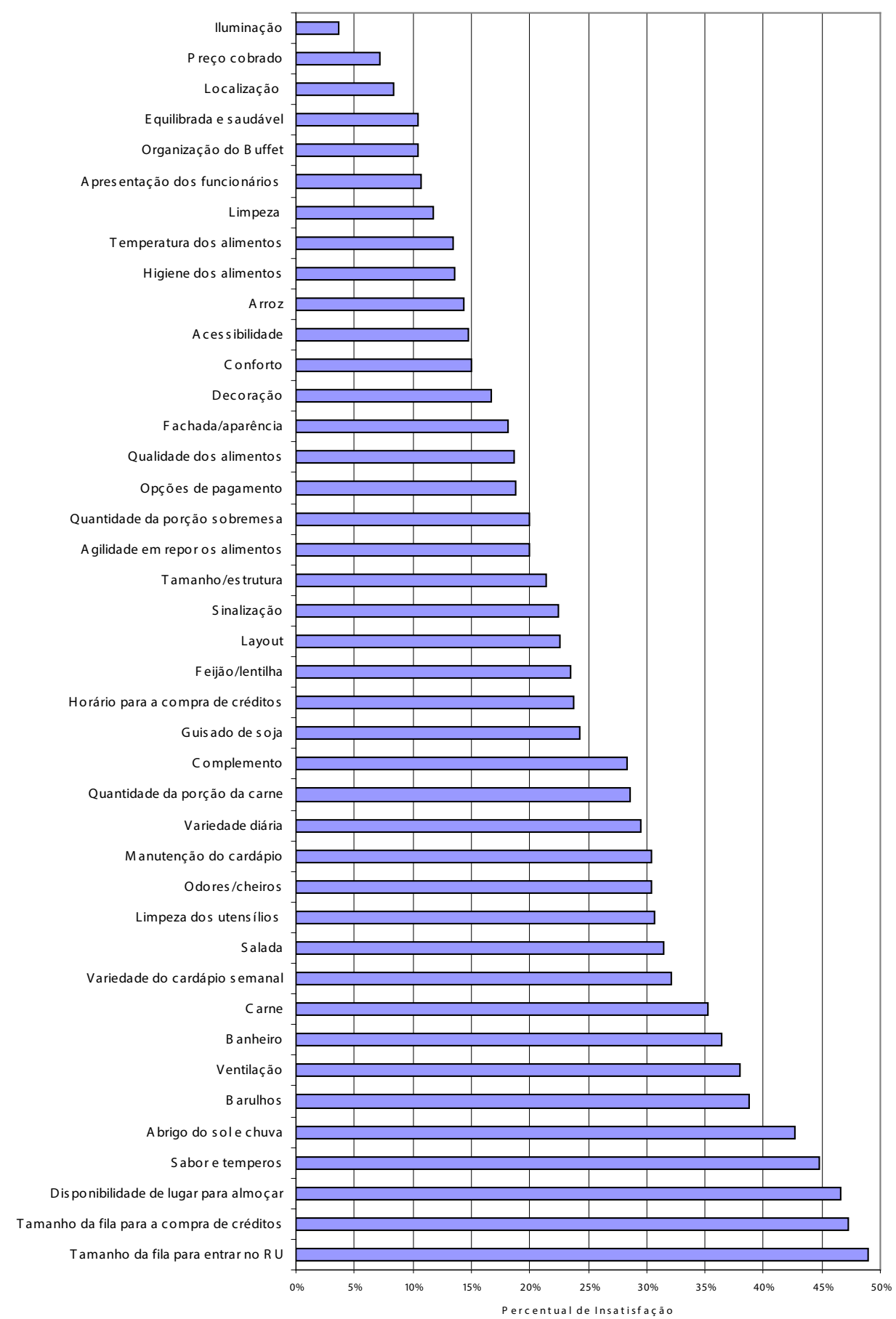

Figura 3 - Percentual de insatisfação de todos os itens avaliados Fonte: Elaborado pelos autores. 


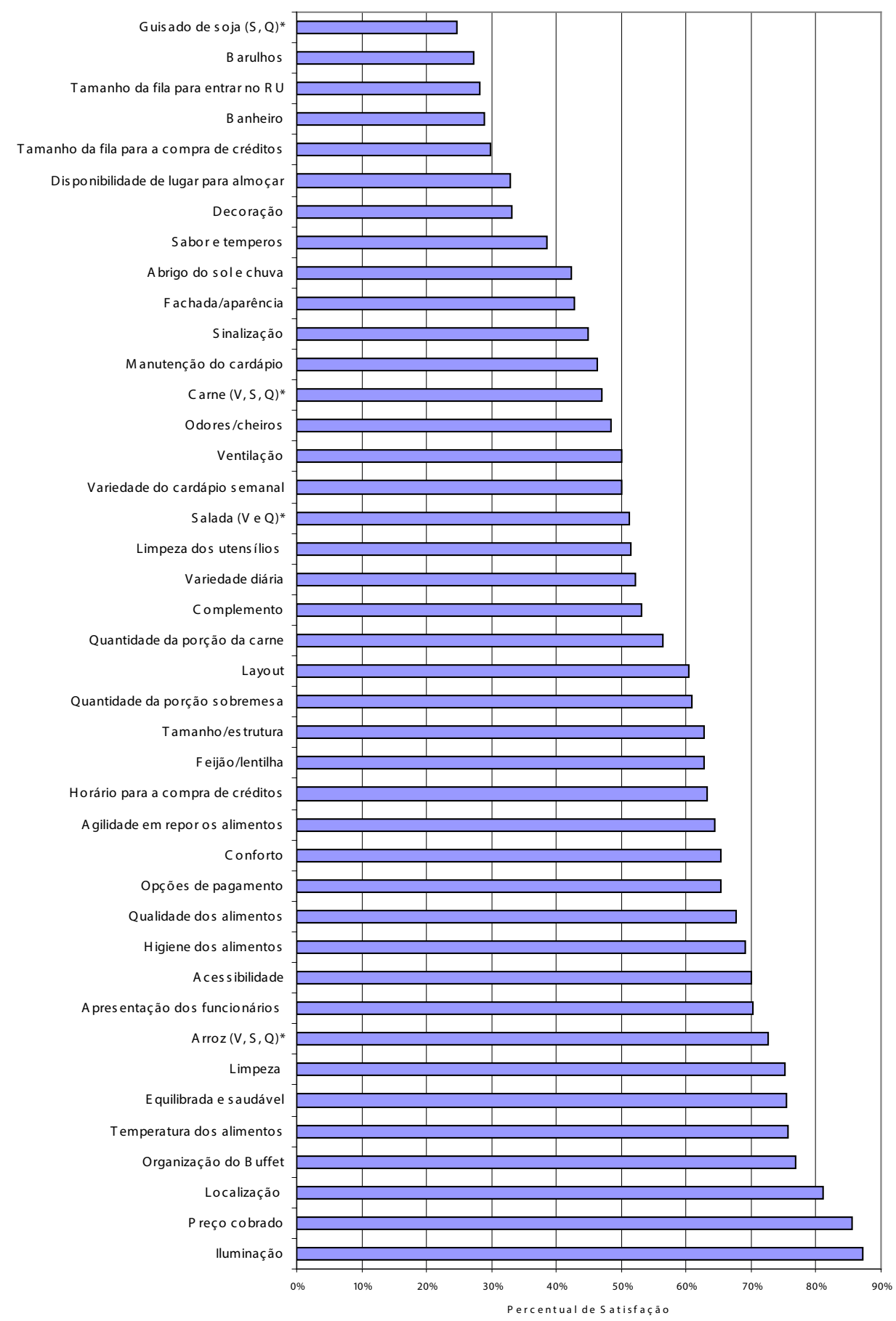

Figura 4 - Percentual de satisfação de todos os itens avaliados Fonte: Elaborado pelos autores. 
A fim de verificar os principais índices de insatisfação por RU (maiores que $40 \%$ ), os dados da Figura 3 foram estratificados segundo o RU (RU do Centro, RU I do Campus e RU II do Campus). As Figuras 5, 6 e 7 apresen- tam os itens com os maiores percentuais de insatisfação para o RU localizado no Centro da cidade, o RU I localizado no Campus e o RU II localizado no Campus, respectivamente.

Figura 5 - Itens com os maiores percentuais de insatisfação no RU Centro

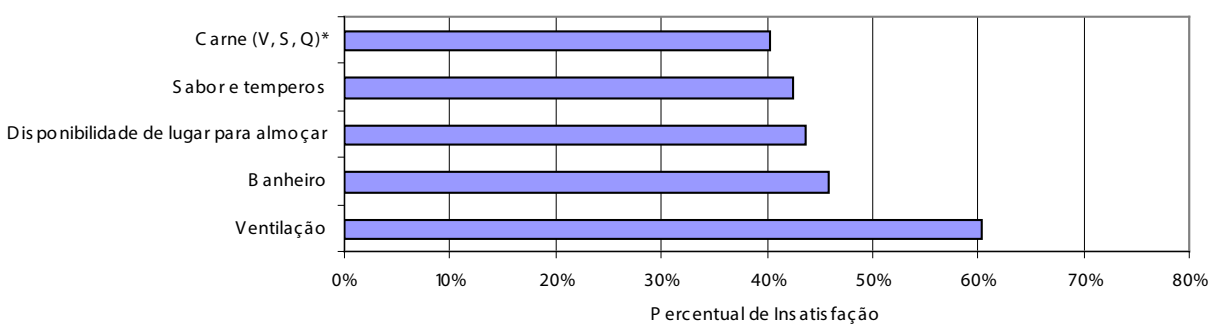

Fonte: Elaborado pelos autores.

Figura 6 - Itens com os maiores percentuais de insatisfação no RU I

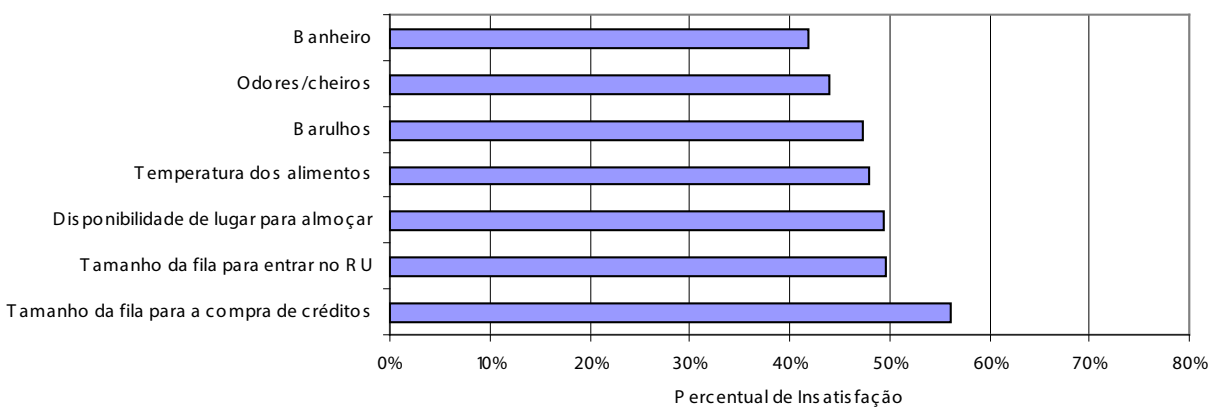

Fonte: Elaborado pelos autores.

Figura 7 - Itens com os maiores percentuais de insatisfação no RU II

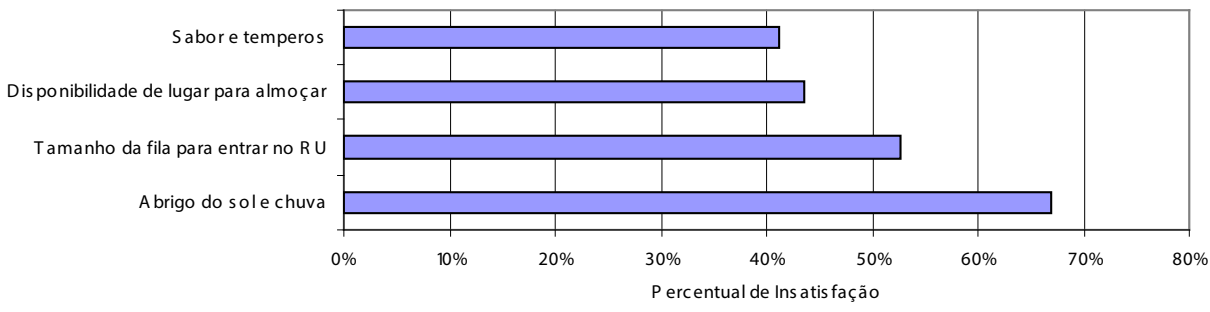

Fonte: Elaborado pelos autores.

Observa-se que o principal problema do RU do Centro é a questão da ventilação (60,4\% de insatisfação), que sequer aparece dentre os maiores problemas dos demais restaurantes. Esse restaurante fica no andar térreo de um prédio da UFSM e possui pouco espaço para circulação de ar. Por outro lado, o tamanho da fila para a compra de créditos destaca-se no RU I do Campus 
como o principal problema $(56,1 \%$ de insatisfação), seguido pelo tamanho da fila para entrar no restaurante $(49,7 \%)$ e pela disponibilidade de mesa e cadeira para almoçar (49,5\%). Percebe-se que os principais níveis de insatisfação do RU I estão relacionados com a grande quantidade de usuários. Já no RU II do Campus, o principal problema é o abrigo contra o sol e a chuva $(66,9 \%$ de insatisfação), que é insuficiente para acomodar o tamanho da fila para entrar no RU (52,7\%). A condição dos banheiros desponta dentre os maiores índices de insatisfação no RU do Centro e no RU I, enquanto que a disponibilidade de mesa e cadeira para almoçar é um dos principais problemas em todos os restaurantes. Problemas com barulhos, odores e cheiros destacam-se no RU I do Campus.

\section{Considerações finais}

Este trabalho teve como objetivo principal avaliar o nível de satisfação dos usuários das três unidades do Restaurante Universitário (RU) da Universidade Federal de Santa Maria, Rio Grande do Sul. Os resultados desta pesquisa serão encaminhados à administração do $\mathrm{RU}$, onde poderão gerar subsídios para a formulação de propostas que visem a melhorias (mudanças e/ ou adaptações) nos setores avaliados.

$\mathrm{Na}$ primeira etapa do trabalho, realizou-se uma análise descritiva, que permitiu obter informações sobre o perfil dos usuários do RU. Observou-se que a maioria é composta de pessoas do sexo feminino e de pessoas solteiras situadas na faixa etária de 17 a 30 anos.Grande parte consiste em alunos sem benefício socioeconômico, que estão vinculados a cursos de graduação e costumam almoçarem grupo. A maioria prefere frequentar o estabelecimento do meio-dia às 13 horas e, pelo menos, três vezes por semana. Os RU's do Campus recebem o maior contingente de usuários, pois atendem mais cursos e possuem maior estrutura do que o RU do Centro. Almoçar no RU é uma opção escolhida principalmente pelo preço atrativo e pelo fato de o restaurante localizar-se próximo ao local onde os usuários realizam suas atividades dentro da UFSM. Poucos usuários disseram ser vegetarianos.

Ao responder a pesquisa, os usuários avaliavam os atributos do RU, segundo o seu nível de satisfação, de acordo com uma escala likert de cinco pontos. Foram avaliados atributos relacionados com o ambiente interno e externo, com a alimentação e com o atendimento dos funcionários do RU.

A maioria dos atributos foi avaliada de forma positiva, com destaque para a iluminação interna, o preço cobrado, a localização, a acessibilidade, as formas de pagamento, o atendimento, o tamanho do restaurante, a organização do buffet, o conforto e o layout. Também foram considerados bastante satisfatórios os itens relacionados à limpeza e higiene e à qualidade dos alimentos. Foram observados, assim, muitos elogios relacionados a esses aspectos, principalmente quanto ao baixo preço cobrado em relação à qualidade dos alimentos disponibilizado no buffet .

Com relação aos itens avaliados insatisfatoriamente, no geral, observase que alguns foram atributos a um RU específico e outros foram comuns a todos os RU's. A dificuldade em encontrar lugar disponível para sentar e almoçar, após se servir, é um problema em todos os RU's. Aparentemente, a ampliação do RU I do Campus e a construção do RU II no Campus não acompanharam, de forma proporcional, o crescimento da Universidade nos últimos anos, devido à criação de novos cursos e ao aumento do número de vagas. O problema da ventilação destaca-se fortemente dos demais itens no RU do Centro. Já o RU I, mesmo tendo sido ampliado, ainda sofre com o excesso de demanda no almoço. E o RU II, apesar de ter sido construído há pouco tempo, já apresen- 
ta problemas em relação ao abrigo contra o sol e a chuva, devido ao tamanho da fila para entrar no restaurante. Os resultados permitiram identificar os critérios avaliados insatisfatoriamente que devem receber prioridade nas ações de melhorias a serem realizadas em cada uma das três unidades de RU.

Outras informações foram obtidas por meio de um espaço no questionário destinado para comentários, sugestões e críticas. Nesse espaço, além dos problemas já mencionados, os usuários reclamaram da inexistência de saleiros, da porção de carne (alguns gostariam de receber um pedaço maior e outros um pedaço menor) e da qualidade das carnes de peixe e de porco. Outros usuários sugeriram maior variação nas saladas e na carne, disponibilidade de mesas e cadeiras mais altas, um vidro no buffet para proteger os alimentos e melhor acesso para cadeirantes, portadores de deficiência física e gestantes.

O presente trabalho foi realizado utilizando uma metodologia consistente, com um questionário bem-elaborado e diversificado. No entanto, como as questões eram objetivas, pode haver alguma limitação com relação a identificar o motivo pelo qual os usuários estão insatisfeitos com determinado item, embora estes pudessem se manifestar no espaço destinado a sugestões. Com relação ao método de coleta dos dados, a pesquisa foi realizada por meio da internet, tratando-se, portanto, de uma amostra não probabilística. Há limitações nesse tipo de amostragem, pois não é possível calcular o erro amostral nem fazer inferências com intervalos de confiança nem outro teste estatístico baseado nas suposições de uma amostra aleatória. Em função disso, essa pesquisa se limita a fazer apenas uma análise descritiva. Apesar das limitações existentes, a obtenção de uma amostra grande contribuiu para minimizar esses problemas e melhorar a precisão dos resultados. Estes corroboram o conhecimento dos autores deste trabalho com relação ao RU da UFSM, pois também são usuários do restaurante. Como trabalhos futuros, ainda considerando este projeto específico, serão elaboradas análises mais sofisticadas, as quais utilizarão cruzamento entre as variáveis de perfil e o nível de satisfação dos usuários, a fim de verificar se existem associações significativas entre esses itens. Também existe a proposta de elaborar um estudo aplicando técnicas multivariadas, para analisar a dimensionalidade do questionário e identificar a existência de possíveis clusters. Além disso, será feito um estudo comparando a importância dos atributos avaliados com o nível de satisfação dos usuários em relação a esses atributos. Pretende-se, ainda, repetir a pesquisa periodicamente, a fim de verificar o desempenho dos indicadores de satisfação dos usuários.

\section{Referências}

1. ALMANZA, B. A.; MASON, A. C.; WIDDOWS, R.; GIRARD, F. J. Consumer responses to nutrition guidelines labeling in a university restaurant. J Am Diet Assoc., 93, p. 580-581, 1993.

2. ALMEIDA, T. D.; BRITO NETO, J. L.; LAKATOS, M.; MONTEMOR, M. Relação entre o cardápio do Restaurante Universitário e desperdício. Revista Ciências do Ambiente On-Line,v. 4, n. 1, 2008.

3. ALVES, M. S.; SALCEDO, D. A. Indicadores de Qualidade como Instrumento de Gestão: um estudo de caso no Restaurante Universitário da UFPE. In Encontro de Estudos sobre Tecnologia, Ciência e Gestão da Informação (ENEGI), V, Anais..., 2014.

4. BISOGNI, C. A.; JASTRAN, M.; BLAKE, C. E. The construction of eating episodes, food scripts and food routines. In International Handbook of Behavior, Diet, and Nutrition. PREEDY V. R., WATSON R. R., MARTIN C. 
R. New York: Springer, pp. 987-1009, 2011.

5. BRAGA, A. C.; PEREIRA, T. L; ANDRADE JUNIOR, P. P. Avaliação de Restaurante Universitário por meio de Indicadores de Qualidade. Desenvolvimento em Questão, Ijuí, v. 13, n. 30,abr./jun. 2015.

6. BRANDÃO, A. R.; GIOVANONI A. Comparação dos cardápios oferecidos em uma unidade de nutrição do município de Teutônia com o programa de alimentação do trabalhador. Revista Destaques Acadêmicos, Lajeado, v. 3, n. 3, 2011.

7. CAIXETA, J. E.; CUNHA, L. F. Avaliação do Restaurante Universitário: um estudo piloto. Série: Textos de Alunos de Psicologia Ambiental, n. 3, 1994.

8. CARVALHO, L. R.; AMORIM, S. L.; TAVARES M. F. Sistema de indicadores de qualidade como ferramenta de gestão em um restaurante universitário: estudo de caso. In: Encontro Nacional de Engenharia de Produção, XXIII, Anais..., 2003.

9. CATTAFESTA, M.; SIQUEIRA, J. H.; PROENCA, L. V. S.; OLISOSA, P. R.; SANTOS, K. V.; MANNATO, L.; SABRINA, T.; MOLINA, M. D. C. B. Condições higiênico-sanitárias de um restaurante universitário e as práticas alimentares de seus usuários. Revista Brasileira de Pesquisa em Saúde,Vitória, v. 14, p. 36-43, 2012.

10. COUTINHO, E. P.; MOREIRA, R. T.; SOUZA, D. M. Aplicação do ciclo de serviços na análise da gestão da qualidade de um restaurante universitário. In: Encontro Nacional de Engenharia de Produção, XXV, Anais..., 2005.

11. CRANAGE, D. A.; CONKLIN, M. T.; LAMBERT, C. U. Effect of nutrition information in perceptions of food quality, consumption behavior and purchase intentions. Journal of Foodservice Business Research,v.7, p. 43-61, 2004.

12. DIPIETRO, R. B.; CAO, Y.;
PARTLOW, C. Green practices in upscale foodservice operations. International Journal of Contemporary Hospitality Management, Bingley,v. 25, n. 5, p. 779-796, 2013.

13. EDWARDS, J. S. A.; MEISELMAN, H. L. The influence of positive and negative cues on restaurant foodchoice and food acceptance. International Journal of Contemporary Hospitality Management, Bingley, v. 17, n. 4, p. 332-344, 2005.

14. FONAPRACE. Realidade dos RUs em 1997. Perfil dos Restaurantes Universitários das Instituições de Ensino Superior do País, 1997. Disponível em<http://www.ufrn.br/sites/fonaprace/ rus.html >. Acesso em 24/06/2013.

15. FREEDMAN, M. R. Point-of-Selection Nutrition Information Influences Choice of Portion Size in an Al1-You-Can-Eat University Dining Hall. Journal of Foodservice Business Research, Philadelphia, v. 14, n. 1, 2011.

16. GARCEZ, E. M. S.; FACHIN, G. R. B. ;ANDRADE JÚNIOR, P. P. Indicadores da qualidade em restaurantes: um estudo de caso. Revista de Ciências da Administração, Florianópolis, v. 2, n. 3, p. 29-38, 2000.

17. GARDIN, E. T. O.; CRUVINEL, E. B. S. Avaliação da satisfação dos clientes do restaurante universitário (RU) do Campus Londrina da Universidade Tecnológica Federal do Paraná. Trabalho de Conclusão de Curso. Curso Superior de Tecnologia em Alimentos. Universidade Tecnológica Federal do Paraná - UTFPR, Londrina, 2014.

18. GASPARIN, E. et al. Perfil nutricional e percepção de conforto dos comensais do Restaurante Universitário da UTFPR - Campus Medianeira. In: Seminário de Iniciação Científica e Tecnológica da UTFPR, XVII, Anais...,Curitiba, PR, Brasil, 07 e 08 de Novembro de 2012. 
19. GIL, A. C. Como elaborar projetos de pesquisa. São Paulo: Atlas, 2002.

20. GRÁCIA, M. A. Parâmetros indicadores de qualidade de carne moída utilizada em restaurantes de coletividade. Dissertação de Mestrado. Universidade Federal do Paraná. Curitiba, 2011.

21. HÄRTER, A. C; SILVA, C. E. S. F.; SNEYDER, D.; SIQUEIRA, R. F. Estudo de Caso Sobre a Satisfação dos usuários do Restaurante UniversitárioRU. Revista de Estudos Sociais,Cuiabá, v. 15, n. 30, 2013.

22. JACOB, A. V. et al. Avaliação da satisfação dos clientes e diagnóstico de filas no Restaurante Universitário Noturno da UFSC. In: Semana de Engenharia de Produção Sul-Americana, VI, Anais..., Florianópolis, SC, Brasil, Novembro de 2006.

23. KLASSEN, K; KUMAR, A.; TRYBUS, E. Planning food services for a campus setting.Internacional Journal of Hospitality Management, v. 24, n. 4, 579-609, 2005.

24. KING, J. P; JAMIL, S. M. Level of satisfaction among postgraduate health sciences students on the cafeteria facilities in Universiti Kebangsaan Malaysia, Kuala Lumpur Campus. International Journal of Quality and Service Sciences, Bingley, v. 6, n. 4, p. $258-273$, 2014.

25. MAIA, T. M. L. Planejamento e gestão estratégica para 0 restaurante universitário da UFC em um cenário de expansão do número de alunos. Dissertação de Mestrado, Universidade Federal do Ceará. Fortaleza, 2008.

26. MAlhotra, N. K. Pesquisa de marketing: uma orientação aplicada.3. ed. Porto Alegre: Bookman, 2001

27. MARQUES, C. S.; PEREIRA, B. A. D.; ALVES, J. N. Identificação dos principais fatores relacionados à infra -estrutura universitária: Uma análise em uma IES pública. Sociais e Huma- nas, Santa Maria, v. 23, n. 01, p. 91$103,2010$.

28. MCDANIEL, C. D.; GATES, R. Pesquisa de marketing. São Paulo: Thomson Learning, 2006.

29. MEC, Ministério da Educação e Cultura. Assistência ao estudante universitário. Restaurantes Universitários. Relatório de grupo de trabalho. Brasília, 1984.

30. MEDEIROS, L. G. F. MELLO, L. T. C.; ARAÚJO. I. D. L.; BULHÕES, L. A. A gestão de processos como fonte de melhorias: aplicação de técnicas de mapeamento de processos em um Restaurante Universitário. In: Congresso Nacional de Excelência em Gestão (CNEG), IX, Anais..., 2013.

31. MILET, E. B. Qualidade em serviços: princípios para a gestão contemporânea das organizações. Rio de Janeiro: Ediouro, 1997.

32. MOURA, M. A. P. et al. Grau de satisfação dos alunos da Universidade Federal do Piauí em relação aos serviços prestados pelo Restaurante Universitário do Campus Ministro Reis Velloso, em Parnaíba - PI. In: Congresso Internacional de Administração, Anais...,Ponta Grossa, PR, Brasil, 22 a26 de Setembro de 2014.

33. NG, Y. N. A study of customer satisfaction, return intention, and word -of-mouth endorsement in university dining facilities. Master's Thesis. Faculty of the Graduate College. Oklahoma State University. Stillwater, Oklahoma, 2005.

34. OLIVEIRA, C. S; ALVES, F. S. Educação nutricional em unidade de nutrição, direcionada para consumo de pratos protéicos um estudo de caso. Alim. Nutr., Araraquara,v. 19, n. 4, p. 435-440, 2008.

35. PASSADOR, J. L.; FILHO, D. O. L.; SPANHOL, P. S.; RODRIGUES, F. S.; SABES, J. J. S. A percepção do consumidor de alimentos "fora de casa": 
um estudo multicaso na cidade de Campo Grande/MS.In: SIMPEP, XIII, Anais..., Bauru, SP, Brasil, 6 a 8 de Novembro de 2006.

36. RESTAURANTE UNIVERSITÁRIO, Universidade Federal de Santa Maria. www.ufsm.br/ru. 2012? Acesso em 20/11/2013.

37. RESTAURANTE UNIVERSITÁRIO. Pesquisa de opinião RU/UFSC. Universidade Federal de Santa Catarina. Florianópolis, 2013a. Acesso em: 13/03/2015. Disponível em: <ru.ufsc. br/files/2013/06/Divulgação-PESQUISA-DE-OPINIÃO.doc $>$.

38. RESTAURANTE UNIVERSITÁRIO. Pesquisa avaliação do RU: Resultado Parcial.Universidade Estadual de Londrina, Londrina, 2013b. Acesso em: 13/03/2015. Disponível em < http:// www.uel.br/ru/pages/arquivos/Resultado\%20Pesquisa\%20RU.doc $>$.

39. RESTAURANTE UNIVERSITÁRIO. Relatório Pesquisa de satisfação dos (as) usuários (as) dos Restaurantes Universitários (RUs) da Universidade Federal de Uberlândia (UFU) 2014.Universidade Federal de Uberlândia, Uberlândia, 2014.Acesso em: 25/05/2015. Disponível em <www. ru.ufu.br/sites/ru.ufu.br/files/files/pesquisa_de_satisfacao_rus.pdf $>$.

40. RICHARDSON, R. J. Pesquisa Social. Métodos e Técnicas. São Paulo: Atlas, 1999.

41. ROHR, A. R.; MASIERO, M. S.; KLIEMANN NETO, F. J. Proposta de um sistema de gestão de custos para o Restaurante Universitário da Universidade federal do Rio Grande do Sul. In: Encontro Nacional de Engenharia de Produção, XXX, Anais..., 2010.

42. ROOS, C.; SARTORI, S.; GODOY, L. P. Modelo de Kano para a identificação de atributos capazes de superar as expectativas do cliente. Revista Produção Online, Florianópolis, v. 9, n. 3, p. 536-550, 2009.
43. ROSSI C. A. V, SLONGO, L. A. Pesquisa de Satisfação de clientes: o Estado-da-Arte e Preposição de um Método Brasileiro. Revista de Administração Contemporânea, Rio de Janeiro, v. 2, n.1, 1998.

44. SARAIVA, M.; CID, M.; BAIÃO, C. The degree of customer satisfaction in university restaurants: the case of the University of Evora in Portugal. EDULEARN11 Conference. Proceedings..., Barcelona, Spain, 4-6 July 2011.

45. SIEBENEICHLER, T.; WIENNINGKAMP, D.; RUCHEL, A.P.; TROMBINI, E. S.; ZAMBERLAN, L. A Satisfação de Clientes de Restaurantes: Uma Avaliação da Satisfação e da Importância dos Atributos. In SemeAd, XI, Anais..., São Paulo, 28 a 29 de agosto de 2008 .

46. TONTINI, G.; SANT'ANA, A. J. Identificação de atributos críticos de satisfação em um serviço através da análise competitiva do gap de melhoria. Gest. Prod., São Carlos, v. 14, n.1, p.43-54, jan. 2007.

47. VICTORIA, M. C. M.; FERRARI, C. S.; CHIATTONE, P. V.; SIQUEIRA, E. B.; ZAMBIAZI, R. C. Avaliação das práticas de preparo de alimentos no Restaurante Universitário da Universidade Federal de Pelotas/RS. In: Congresso Brasileiro de Ciências e Tecnologia de Alimentos, XVIII, Anais... Porto Alegre: SBCTA, 2003.

48. VIDRIK, K. N. Indicadores de Qualidade do Restaurante Universitário da Universidade do Sagrado Coração - Bauru, SP: Um estudo de caso. Dissertação de Mestrado, Universidade Anhembi Morumbi. São Paulo, 2008 . 